\title{
TGR5-HNF4a axis contributes to bile acid-induced gastric intestinal metaplasia markers expression
}

\author{
Zhen Ni@ ${ }^{1,2}$, Yali Min ${ }^{3}$, Chuan Han ${ }^{4}$, Ting Yuan ${ }^{5}$, Wenquan Lu', Hassan Ashktorab', Duane T. Smoot ${ }^{8}$, Qiong Wu',
} Jian $\mathrm{Wu}^{1}$, Weizheng Zeng ${ }^{2}$ and Yongquan Shi (1)

\begin{abstract}
Intestinal metaplasia (IM) increases the risk of gastric cancer. Our previous results indicated that bile acids (BAs) reflux promotes gastric IM development through kruppel-like factor 4 (KLF4) and caudal-type homeobox 2 (CDX2) activation. However, the underlying mechanisms remain largely elusive. Herein, we verified that secondary BAs responsive Gprotein-coupled bile acid receptor 1 (GPBAR1, also known as TGR5) was increased significantly in IM specimens. Moreover, TGR5 contributed to deoxycholic acid (DCA)-induced metaplastic phenotype through positively regulating KLF4 and CDX2 at transcriptional level. Then we employed PCR array and identified hepatocyte nuclear factor $4 a$ $(\mathrm{HNF} 4 \mathrm{a})$ as a candidate mediator. Mechanically, DCA treatment could induce HNF4a expression through TGR5 and following ERK1/2 pathway activation. Furthermore, HNF4a mediated the effects of DCA treatment through directly regulating KLF4 and CDX2. Finally, high TGR5 levels were correlated with high HNF4a, KLF4, and CDX2 levels in IM tissues. These findings highlight the TGR5-ERK1/2-HNF4a axis during IM development in patients with BAs reflux, which may help to understand the mechanism underlying IM development and provide prospective strategies for IM treatment.
\end{abstract}

\section{Introduction}

Gastric cancer (GC) remains one of the most prevalent malignancies worldwide ${ }^{1}$. As a precancerous lesion, intestinal metaplasia (IM) significantly increases the risk of $\mathrm{GC}^{2,3}$. Although phenotypic changes and histopathological characteristics are relatively well-understood, the underlying pathogenesis of IM remains obscure.

Helicobacter pylori $(\mathrm{Hp})$ infection is an established etiologic factor in gastric carcinogenesis ${ }^{4}$. However, $\mathrm{Hp}$ eradication cannot reverse IM phenotype and reduce the risk of GC in patients with $\mathrm{IM}^{5}$. Thus, pathogenic factors other than Hp infection may play important roles in such settings. Previous studies suggested that duodenogastric

\footnotetext{
Correspondence: Yongquan Shi (shiyquan@fmmu.edu.cn)

'State Key Laboratory of Cancer Biology and Institute of Digestive Diseases, Xijing Hospital, Fourth Military Medical University, Xi'an, Shaanxi 710032, China ${ }^{2}$ Department of Gastroenterology, General Hospital of Western Theater Command, Chengdu, Sichuan 610083, China

Full list of author information is available at the end of the article These authors contributed equally: Zhen Ni, Yali Min, Chuan Han Edited by N. Barlev
}

reflux (DGR) contributes to IM and subsequent GC development ${ }^{6}$. Clinical researches indicated that bile acids (BAs) concentrations in gastric juice were positively correlated with the degree of IM regardless of $\mathrm{Hp}$ infection ${ }^{7}$, both in antrum ${ }^{8}$ and cardia ${ }^{9}$. Our previous study first uncovered that BAs exposure could significantly induce gastric epithelial cells columnar genes expression through microRNA-mRNA networks involving a miR-92a-5p/ FOXD1/nuclear factor $-\kappa B(N F-\kappa B)$ axis ${ }^{10}$. These results verified the key role of BAs reflux in gastric IM initiation and progression. However, the underlying mechanisms remain largely unknown.

Intestine developmental signaling pathways reactivation is involved in metaplastic phenotype after pathogenic factors exposure. Kruppel-like factor 4 (KLF4) and caudaltype homeobox 2 (CDX2) are the fundamental transcription factors (TFs) in enterocyte differentiation and maturation ${ }^{11,12}$. Stomach characters loss and intestine features acquisition have been demonstrated in both IM tissues and transgenic mice ${ }^{13-15}$. We previously 
demonstrated that BAs exposure could significantly increase KLF4 and CDX2, and simultaneously inhibit SRY-box 2 expression ${ }^{10,16,17}$. These results indicate that aberrant developmental programs are involved in pathogenic effects of BAs exposure. However, the key events mediating BAs effects and orchestrating KLF4 and CDX2 upregulation in gastric IM development have not been fully clarified.

In the current study, we focused on G-proteincoupled BA receptor 1 (GPBAR1, also known as TGR5), a key receptor that mediated both physiological and pathological effects of secondary BAs. We demonstrated that TGR5 was involved in BA-induced metaplasia process via hepatocyte nuclear factor $4 \alpha$ (HNF4 $\alpha)$ activation. Further, we elucidated that HNF4 $\alpha$ contributed significantly to BA-induced columnar genes expression through directly regulating KLF4 and CDX2. Our findings revealed an important role of TGR5HNF4 $\alpha$ axis in intestine reprogramming caused by chronic BAs reflux in gastric epithelium and subsequent progression of IM.

\section{Materials and methods \\ Reagents and chemicals}

Deoxycholic acid (DCA), SB756050, U0126, SB239063, and MK2206 were purchased from MedChemExpress (Shanghai, China). BI6015 was purchased from Cayman Chemical (Ann Arbor, Michigan, USA). Dimethyl sulfoxide (DMSO) was purchased from Sigma-Aldrich (St. Louis, MO, USA).

\section{Cell culture and treatment}

The human normal gastric epithelial cell line (GES-1) and gastric carcinoma cell lines (AGS, MKN45, BGC823, AZ521, N87, KATO III, and SGC7901) were originally purchased from American Type Culture Collection (ATCC) and maintained in our laboratory. The normal human gastric epithelial cell line HFE-145 was developed and kindly provided by Professor Hassan Ashktorab and Professor Duane T. Smoot. All cell lines were cultured at $37^{\circ} \mathrm{C}$ in a humidified atmosphere of $5 \% \mathrm{CO}_{2}$ in RPMI 1640 medium (Thermo Scientific, Waltham, MA, USA) supplemented with $10 \%$ fetal bovine serum (Biological Industries, Kibbutz Beit Haemek, Israel) and $1 \%$ penicillin-streptomycin solution (Thermo Scientific, Waltham, MA, USA). All cell lines were authenticated by Short Tandem Repeat (STR) DNA profiling and were tested negative for mycoplasma contamination. For BAs treatment, the cells were seeded into $6 \mathrm{~cm}$ culture dishes. After reaching $\sim 60-70 \%$ confluence, the cells were starved for $24 \mathrm{~h}$ and then treated with DCA dissolved in DMSO at the indicated concentrations for different times in medium without fetal bovine serum. For pathway blocking, the cells were pretreated with inhibitors dissolved in DMSO for $1 \mathrm{~h}$ before DCA treatment. The negative control was treated with DMSO.

\section{Total RNA extraction and quantitative real-time RT-PCR}

Total RNA was extracted using the RNeasy Mini Kit (QIAGEN, Hilden, Germany) according to the manufacturer's instructions. In total, $500 \mathrm{ng}$ RNA was synthesized into cDNA using the PrimeScript RT reagent kit (TaKaRa, Shiga, Japan) and Mir-X mRNA First-Strand Synthesis Kit (TaKaRa) in a $10 \mu \mathrm{L}$ volume. Real-time PCR was performed on a CFX96 system using TB Green Premix Ex Taq II (TaKaRa) with $2 \mu \mathrm{L}$ cDNA and $0.8 \mu \mathrm{L}$ primers in a final volume of $20 \mu \mathrm{L}$. The final PCR conditions were as follows: pre-denaturation at $95^{\circ} \mathrm{C}$ for $10 \mathrm{~min}$, followed by 44 cycles at $95^{\circ} \mathrm{C}$ denaturation for $10 \mathrm{~s}, 60^{\circ} \mathrm{C}$ annealing for $20 \mathrm{~s}$, and $72^{\circ} \mathrm{C}$ extension for $10 \mathrm{~s}$. The target gene mRNA was normalized to human glyceraldehyde 3-phosphate dehydrogenase (GAPDH) and calculated using the $2^{-\Delta \Delta C T}$ method. Primer sequences are shown in Table 1.

\section{Western blotting}

Cells were collected and total protein was extracted using RIPA cell lysis buffer (Beyotime Biotechnology,

Table 1 The sequences of primers used in this study.

\begin{tabular}{lll}
\hline Gene symbols & Primers & $\mathbf{5}^{\prime} \mathbf{- 3}^{\prime}$ \\
\hline HNF4a & Forward & GTTCAAGGACGTGCTGCTCCTA \\
& Reverse & AGGCATACTCATTGTCATCGATCTG \\
CDX2 & Forward & TTCACTACAGTCGCTACATCACCA \\
& Reverse & CTGCGGTTCTGAAACCAGATT \\
KLF4 & Forward & AAGAGTTCCCATCTCAAGGCACA \\
& Reverse & GGGCGAATTCCATCCACAG \\
ALPI & Forward & CATTCCAGGTCACCAGATCCA \\
& Reverse & AGAAATCTATGCCCAGCATCCAG \\
MUC13 & Forward & AGAAACATTCCATGGCCTATCAAGA \\
& Reverse & CTTGTCATCAGCACGCATTCA \\
Villin1 & Forward & CGACTGCTACCTGCTGCTCTACAC \\
& Reverse & CGGCTTGATAAGCTGATGCTGTAA \\
MUC5AC & Forward & CTGACCAAGGGCTCCGTC \\
& Reverse & GCAAGGGTGTGGCAGACG \\
GAPDH & Forward & GCACCGTCAAGGCTGAGAAC \\
& Reverse & TGGTGAAGACGCCAGTGGA \\
& Forward & GGCGGAGTCCCGCGCCGAAC \\
& Reverse & TCAAAAAGTGCACACCGAGCC \\
\hline
\end{tabular}

ALPI alkaline phosphatase, intestinal, CDX2 caudal-type homeobox 2, HNF4a hepatocyte nuclear factor 4a, KLF4 Kruppel-like factor 4, MUC13 mucin 13, MUC5AC mucin 5AC. 
Shanghai, China) with protease and phosphatase inhibitor cocktails (MedChemExpress, Shanghai, China). Protein was quantified using the bicinchoninic acid method according to the manufacturer's instructions (Thermo Scientific, Waltham, MA, USA). Proteins $(20-30 \mu \mathrm{g})$ were electrophoresed on a $8-12 \%$ polyacrylamide gel, transferred onto a nitrocellulose membrane (Pall Corporation, Port Washington, NY, USA) at $25 \mathrm{~V}$ for $35 \mathrm{~min}$, and blocked for $1 \mathrm{~h}$ in $10 \%$ non-fat milk in $1 \times$ Tris Buffered Saline (TBS)/0.1\% (v/v) Tween-20 at room temperature. Primary antibodies were added and incubated overnight at $4{ }^{\circ} \mathrm{C}$. Human HNF4 $\alpha(\# 3113,1: 1000)$, CDX2 (\#12306, 1:1000), Villin1 (\#2369, 1:1000), p21 (\#2947, 1:1000), and cadherin-17 (CDH17) (\#42919, 1:1000) were from Cell Signaling Technology (Danvers, MA, USA). Primary antibodies against human KLF4 (ab215036, 1:1000), TGR5 (ab72608, 1:1000), mucin 5AC (MUC5AC) (ab24071, 1:1000), and mucin 13 (MUC13) (ab235450, 1:1000) were from Abcam (Cambridge, UK). Primary antibody against human intestinal alkaline phosphatase (ALPI) (A6226, 1:1000), and $\beta$-actin (AC006, 1:4000) were from ABclonal (Wuhan, China). Second antibodies (horseradish peroxidase-conjugated anti-mouse/rabbit IgG, 1:4000, Cell Signalling Technology) were incubated at room temperature for $1 \mathrm{~h}$. Signals were detected using WesternLumaxLight Sirius HRP substrate reagent (ZETA-Life, San Francisco, CA, USA). All data were normalized to human $\beta$-actin. The bands were scanned using a ChemiDocXRS + Imaging System (Bio-Rad, Hercules, CA, USA) and quantified using Image Lab v5.2 software (Bio-Rad).

\section{Tissues collection and immunohistochemistry}

This study was approved by the Institutional Ethics Committee of First Affiliated Hospital of Fourth Military Medical University. Formalin-fixed, paraffin-embedded normal and IM biopsy specimens from stomach antrum were obtained from the pathology department of Xijing Digestive Disease Hospital. All patients were H. pylori negative confirmed by rapid urease test or ${ }^{13} \mathrm{C}$-breath test. All samples were diagnosed by hematoxylin and eosin staining by at least two pathology experts and were classified into normal stomach tissues, mild IM (goblet cells percentage $<1 / 3$ ), moderate IM (goblet cells percentage 1 / $3-2 / 3$ ), and severe IM (goblet cells percentage $\geq 2 / 3$ ) according to the proportion of the gastric glands being replaced by the metaplastic issue ${ }^{18,19}$. Paraffin-embedded consecutive slides of gastric disease tissue microarrays (ST8017a, ST806, and IC00011b) including 67 cases of chronic superficial gastritis and 120 cases of IM were purchased from Alenabio (Xi'an, China).

Immunohistochemistry (IHC) staining was performed for TGR5, HNF4 $\alpha$, P1-HNF4 $\alpha$, P2-HNF4 $\alpha$, CDX2, and
KLF4 in stomach tissues using the standard BiotinStreptavidin HRP Detection Kit (Zsbio, Beijing, China). Briefly, tissue slides were dewaxing and hydration using dimethylbenzene and ethanol. Next, $3 \% \mathrm{H}_{2} \mathrm{O}_{2}$ was used to eliminate endogenous peroxidase activity for $10 \mathrm{~min}$ at room temperature. Antigen retrieval was carried out by heat treatment in $1 \times$ citrate buffer for $2 \mathrm{~min}$ and then cooling the sections to room temperature. Primary antibodies against human HNF4 $\alpha$ (\#3113, 1:400, Cell Signaling Technology), KLF4 (ab215036, 1:1000, Abcam), CDX2 (\#12306, 1:100, CST), P1-HNF4 $\alpha$ (ab41898, 1:100, Abcam), P2-HNF4 $\alpha$ (PP-H6939-00, 1:100, R\&D), and TGR5 (ab72608, 1:300, Abcam) were incubated overnight at $4{ }^{\circ} \mathrm{C}$. A secondary antibody $(1: 400)$ was added and incubated for $30 \mathrm{~min}$ at room temperature. Diaminobenzidine (DAB) reagent was added for 1-3 min at room temperature. Finally, the slides were rinsed with running water and counterstained with hematoxylin for $2 \mathrm{~min}$. A concentration-matched nonspecific rabbit IgG was used as a control.

The slides were scanned and viewed using Pannoramic Viewer (3DHISTECH, Ltd, Budapest, Hungary). The staining intensity of $H N F 4 \alpha, C D X 2$, and KLF4 was semiquantitatively determined using the $\mathrm{H}$-score method ${ }^{20}$. Only nuclei stained unequivocally were considered as positive. An $H$-score $\geq 50$ is considered positive. TGR5 expression was semi-quantitatively determined according to the staining intensity and percentage of positive cells $\mathrm{s}^{21}$. IHC scores $<6$ and $\geq 6$ were considered as low and high expression, respectively.

\section{Immunofluorescence}

To detect the expression of HNF4 $\alpha$, CDX2, and KLF4 induced by DCA treatment, $3 \times 10^{4}$ GES- 1 cells were cultured on a Millicell EZ SLIDE 4-well glass slide (Merck, Darmstadt, Germany). On the next day, the cells were starved for $24 \mathrm{~h}$ and then treated with DCA for another $24 \mathrm{~h}$. The cells were fixed with $4 \%$ paraformaldehyde for $30 \mathrm{~min}$ and washed with phosphatebuffered saline (PBS) three times. The cells were treated with $0.5 \%$ Triton-X 100 for 30 min and then blocked with blocking solution (Hat Biotechnology, Xi'an, China) for $30 \mathrm{~min}$ at room temperature. The cells were stained with primary antibodies against HNF4 $\alpha$ (\#3113, 1:400, CST), KLF4 (ab215036, 1:100, Abcam), and CDX2 (\#12306, 1:50, CST) overnight at $4{ }^{\circ} \mathrm{C}$. After washing with $1 \times \mathrm{PBS} / 0.1 \%$ $(\mathrm{v} / \mathrm{v})$ Tween-20 three times, the cells were incubated with Alexa Fluor 594-conjugated secondary antibodies (1:250, Yeasen Biotech, Shanghai, China) at room temperature for $1 \mathrm{~h}$. Cell nuclei were stained with 4',6-diamidino-2phenylindole $(1: 500$, CST) for $5 \mathrm{~min}$. Fluorescence was scanned using a Nikon A1R Confocal Microscope (Tokyo, Japan). 


\section{RT2 profiler PCR array analysis of GES-1 cells treated with and without DCA}

Total RNA of GES-1 cells treated with and without $200 \mu \mathrm{M}$ DCA for $24 \mathrm{~h}$ in a 6-well culture plate was extracted using an RNeasy Mini Kit (Qiagen) according to the manufacturer's instructions. RNA was purified and cDNA was synthesized from $1 \mu \mathrm{g}$ total RNA using the RT2 First Strand Kit (Qiagen) according to the manufacturer's instructions. Human TFs RT2 Profiler PCR Arrays (\#PAHS-075ZA, Qiagen) were used for TFs profiling using the CFX96 system. PCR array data were analyzed according to the manufacturer's instructions using a Microsoft Excel Template available from the manufacturer's website. Each array contained five housekeeping genes $(A C T B, B 2 M, G A P D H, H P R T 1$, and $R P L P O)$ against which the sample data were normalized. The transcript level of each gene was quantified according to the $2^{-\Delta \Delta C T}$ method. CT values $>35$ were not included in the analysis and considered as negative.

\section{Cell transfection}

The human HNF4 $\alpha 2$ (NM_000457) and HNF4 $\alpha 8$ (NM_175914) overexpression lentiviral was constructed by GeneCopoeia (Rockville, MD, USA). TGR5 (NM_001077191) and CDX2 (NM_001265) overexpression lentiviral and short hairpin RNAs (shRNAs) against human HNF4 $\alpha$ and CDX2 (Table 2) were designed and constructed by GeneChem (Shanghai, China). Small interfering RNA (siRNA) duplexes against human TGR5 and KLF4 were designed and constructed by GenePharma (Shanghai, China) (Table 2).

To establish stable transfection cell lines, GES-1 and AGS $\left(1 \times 10^{5}\right)$ cells were infected with concentrated lentiviral stock at $\sim 50$ multiplicity of infection at a final concentration of $0.5 \mu \mathrm{g} / \mathrm{mL}$ polybrene for $10 \mathrm{~h}$ at $37^{\circ} \mathrm{C}$ in 24-well culture plates. After transferring the cells into $25 \mathrm{~cm}^{2}$ flasks, a final concentration of $1 \mu \mathrm{g} / \mathrm{mL}$ puromycin was added to remove uninfected cells. The cell culture medium was replaced every 2-3 days with fresh and puromycin-containing RPMI 1640.

For transient transfection, after reaching $\sim 70 \%$ confluence in a six-well culture plate, the cells were transfected with $150 \mathrm{nmol}$ of siRNA plasmid with $7.5 \mu \mathrm{L}$ of EndoFectin $^{\mathrm{TM}}$ Max (GeneCopoeia) transfection reagent in $1.5 \mathrm{~mL}$ Gibco $^{\mathrm{TM}}$ Opti-MEM ${ }^{\mathrm{TM}}$ medium for $10 \mathrm{~h}$ at $37^{\circ} \mathrm{C}$. The medium was replaced with fresh RPMI 1640 medium. A scrambled sequence was used as a negative control. Target genes were examined at $72 \mathrm{~h}$ after transfection using western blotting (WB).

The effect of DCA on HNF4 transcription activity was examined using HNF4 transcriptional response element (HNF4 TRE) plasmids with a Gaussia Luciferase reporter designed and constructed by GeneCopoeia. Briefly, GES-1 cells were seeded into a six-well culture
Table 2 The sequences of shRNAs and siRNAs used in this study.

\begin{tabular}{lll}
\hline Gene symbols & Sequences & $\mathbf{5}^{\prime}$-3' \\
\hline Human HNF4a & Sense & CGAGCAGATCCAGTTCATCAA \\
& Antisense & TTGATGAACTGGATCTGCTCG \\
Human KLF4-1 & Sense & CCUUACACAUGAAGAGGCATT \\
& Antisense & UGCCUCUUCAUGUGUAAGGTT \\
Human KLF4-2 & Sense & CAGCCAGAAAGCACUACAATT \\
& Antisense & UUGUAGUGCUUUCUGGCUGTT \\
Human CDX2 & Sense & AGCCCTTGAGTCCGGTGTCTT \\
& Antisense & AAGACACCGGACTCAAGGGCT \\
Human TGR5-1 & Sense & CCUGUACCUCGAAGUCUAUTT \\
& Antisense & AUAGACUUCGAGGUACAGGTT \\
Human TGR5-2 & Sense & GUCGACCUGGACUUGAACUTT \\
& Antisense & AGUUCAAGUCCAGGUCGACTT \\
Human TGR5-3 & Sense & UCGUCUACUUGGCUCCCAATT \\
& Antisense & UUGGGAGCCAAGUAGACGATT \\
Negative Control & Sense & UUCUCCGAACGUGUCACGUTT \\
& Antisense & ACGUGACACGUUCGGAGAATT \\
\hline
\end{tabular}

CDX2 caudal-type homeobox 2, HNF4a hepatocyte nuclear factor $4 a, K L F 4$ Kruppel-like factor 4, shRNAs short hairpin RNA, siRNAs small interfering RNAs, TGR5 G-protein-coupled bile acid receptor 1 .

plate. After reaching $\sim 70 \%$ confluence, the cells were transfected with $2 \mu \mathrm{g}$ HNF4 TRE or negative control plasmids with $10 \mu \mathrm{L}$ of EndoFectin ${ }^{\mathrm{TM}}$ Max transfection reagent in $2 \mathrm{~mL}$ Gibco $^{\mathrm{TM}}$ Opti-MEM ${ }^{\mathrm{TM}}$ medium for $10 \mathrm{~h}$ at $37^{\circ} \mathrm{C}$. Twenty-four hours after transfection, the cells were treated with $200 \mu \mathrm{M}$ DCA for another $24 \mathrm{~h}$. Next, $100 \mu \mathrm{L}$ supernatant was collected and Gaussia Luciferase activity was detected using a Secrete-Pair Gaussia Luciferase Assay Kit (GeneCopoeia) according to the manufacturer's instructions.

\section{Dual-luciferase reporter assays}

Briefly, $2000 \mathrm{bp}$ fragments of the human KLF4 and CDX2 promoter were obtained from Ensembl and predicted in the JASPAR database (http://jaspar.binf.ku.dk). The wild-type and corresponding mutational KLF4 promoter fragments covering the HNF4-binding site and CDX2 promoter fragments covering the HNF4-binding sites were PCR-amplified and cloned into the firefly luciferase reporter plasmid pGL3-basic vector (Promega, Madison, WI, USA). Luciferase activity was then detected using a Dual-Luciferase Reporter assay kit (Promega) at $48 \mathrm{~h}$ after reporter transfection by Lipofectamine 2000 transfection reagent (Invitrogen, Carlsbad, CA, USA) in GES-1 or AGS cells. Firefly luciferase activity was normalized to Renilla luciferase activity and the final data 
were presented as the fold induction of luciferase activity compared with that of the negative control.

\section{Chromatin immunoprecipitation}

Chromatin immunoprecipitation (ChIP) assays were performed using the EZ ChIP ${ }^{\mathrm{TM}}$ ChIP Kit (Millipore, Billerica, MA, USA). The cells were cross-linked with $1 \%$ formaldehyde for $10 \mathrm{~min}$ at $37^{\circ} \mathrm{C}$ and quenched with $2.5 \mathrm{M}$ glycine for $5 \mathrm{~min}$ at room temperature. DNA was immunoprecipitated from the sonicated cell lysates using HNF4 $\alpha$ antibody (Abcam) and subjected to PCR to amplify the HNF4-binding site (Table 1). The amplified fragments were analyzed on an agarose gel. A nonspecific antibody against IgG served as a negative control.

\section{Statistical analysis}

All cell culture experiments were performed in triplicate to reduce error and ensure reproducibility. All quantitative data were expressed as the means \pm SEM. Differences between two groups were examined using two-tailed Student's $t$-test. Differences between multiple groups were compared by one-way analysis of variance with Dunnett's post hoc tests. All categorical data were expressed as rates. Differences between two groups were examined by $\chi^{2}$-test. The correlation between HNF4 $\alpha$, CDX2, and KLF4 expression was examined using Spearman's correlation analysis. Statistical analysis was performed using SPSS 13.0 software (SPSS, Inc., Chicago, IL, USA) or GraphPad Prism 5.0 (GraphPad Software, San Diego, CA, USA). $P<0.05$ was considered statistically significant $\left(" P<0.05,{ }^{* *} P<0.01\right)$.

\section{Results}

DCA treatment induced metaplasia markers expression in gastric epithelial cells

Our previous results have demonstrated that primary BAs chenodeoxycholic acid (CDCA) treatment could significantly induce metaplasia markers expression in vitro ${ }^{10,16}$. Clinical researches indicate that second BAs, especially DCA, are more toxic and are the predominant BAs refluxate in stomach ${ }^{22}$.

Herein, we initially detected both columnar and stomach specific genes expression in gastric epithelial cells (Supplementary Fig. S1a, b). Then, both GES-1 and HFE145, two immortalized human gastric epithelial cell lines, were chosen in the following phenotypic experiments. GES-1, AGS, and BGC823 were chosen in the following gene loss- and gain-of-function experiments. We first treated GES-1 cells with DCA in a dose-dependent manner $(0,50,100,150$, and $200 \mu \mathrm{M})$. The quantitative reverse-transcriptase PCR (qRT-PCR) results showed that DCA treatment could significantly increase KLF4, CDX2, and Villin1 mRNA expression with the highest in $200 \mu \mathrm{M}$ (Fig. 1a). Furthermore, WB results also showed that KLF4,
CDX2, and CDH17 were all increased significantly (Fig. 1b). Simultaneously, DCA treatment significantly inhibited MUC5AC expression in GES-1 cells (Fig. 1a, b). Next, both the GES-1 and HFE-145 cell lines were treated with $200 \mu \mathrm{M}$ DCA in a time-dependent manner $(0,0.5,1$, 2, 4, 8, and 24h). The results showed that CDX2, KLF4, Villin1, and p21 were all increased dramatically (Fig. 1c). Finally, GES-1 cells were treated with $200 \mu \mathrm{M}$ DCA for $24 \mathrm{~h}$ and the immunofluorescence (IF) results further revealed increased nucleus expression of CDX2 and KLF4 (Fig. 1d). Together, these results suggest that DCA could induce metaplasia markers and suppress stomach marker in gastric epithelial cells.

\section{TGR5 promoted metaplasia markers expression and was involved in gastric IM process}

TGR5 is the G-protein-coupled receptor-mediated DCA effects ${ }^{23}$. To explore the role of TGR5 in gastric IM process, we initially examined TGR5 expression in normal and IM tissues. IHC results showed significant positive cell cytoplasm and membrane staining of TGR5 in gastric IM tissues compared with normal tissues (Fig. 2a). Further, the cases with high TGR5 expression were significantly more in IM than in normal tissues (Fig. $2 \mathrm{~b}$ ). Then we detected the expression levels of TGR5 in gastric epithelial cell lines (Supplementary Fig. S1c). After that, we treated GES-1 cells with TGR5 agonist SB756050 and results showed that KLF4 and CDX2 expression was significantly increased (Fig. 2c). Further, TGR5 overexpression in GES-1 cells could significantly induce KLF4 and CDX2 expression on both mRNA and protein levels (Fig. 2d). In contrast, we transfected AGS cells with siRNAs target TGR5 and found that KLF4 and CDX2 protein levels were significantly suppressed (Fig. 2e). Lastly, GES-1 cells were transfected with siRNA target TGR5 following DCA treatment $(200 \mu \mathrm{M})$. The results indicated that TGR5 blocking could significantly alleviate DCAinduced KLF4 and CDX2 expression (Fig. 2f). Together, these results indicate that TGR5 is a key mediator during BA-induced metaplasia markers expression.

\section{Transcription factors profiling identified HNF4a as a key mediator after DCA exposure}

To identify the TFs downstream DCA-TGR5 pathway, we treated GES-1 cells with DCA $(200 \mu \mathrm{M})$ for $24 \mathrm{~h}$ and examined differentially expressed TFs using RT2 Profiler PCR Array. Finally, total 46 differentially expressed TFs were detected (fold-change $\geq 2.0$ and $\leq 2.0,42$ upregulated and 4 downregulated) compared with in control cells (Fig. 3a and Table 3).

The Kyoto Encyclopedia of Genes and Genomes (KEGG) pathway analysis by WebGestalt ${ }^{24}$ (http://www. webgestalt.org) showed that, among these changed TFs, maturity onset diabetes in young pathway was most 


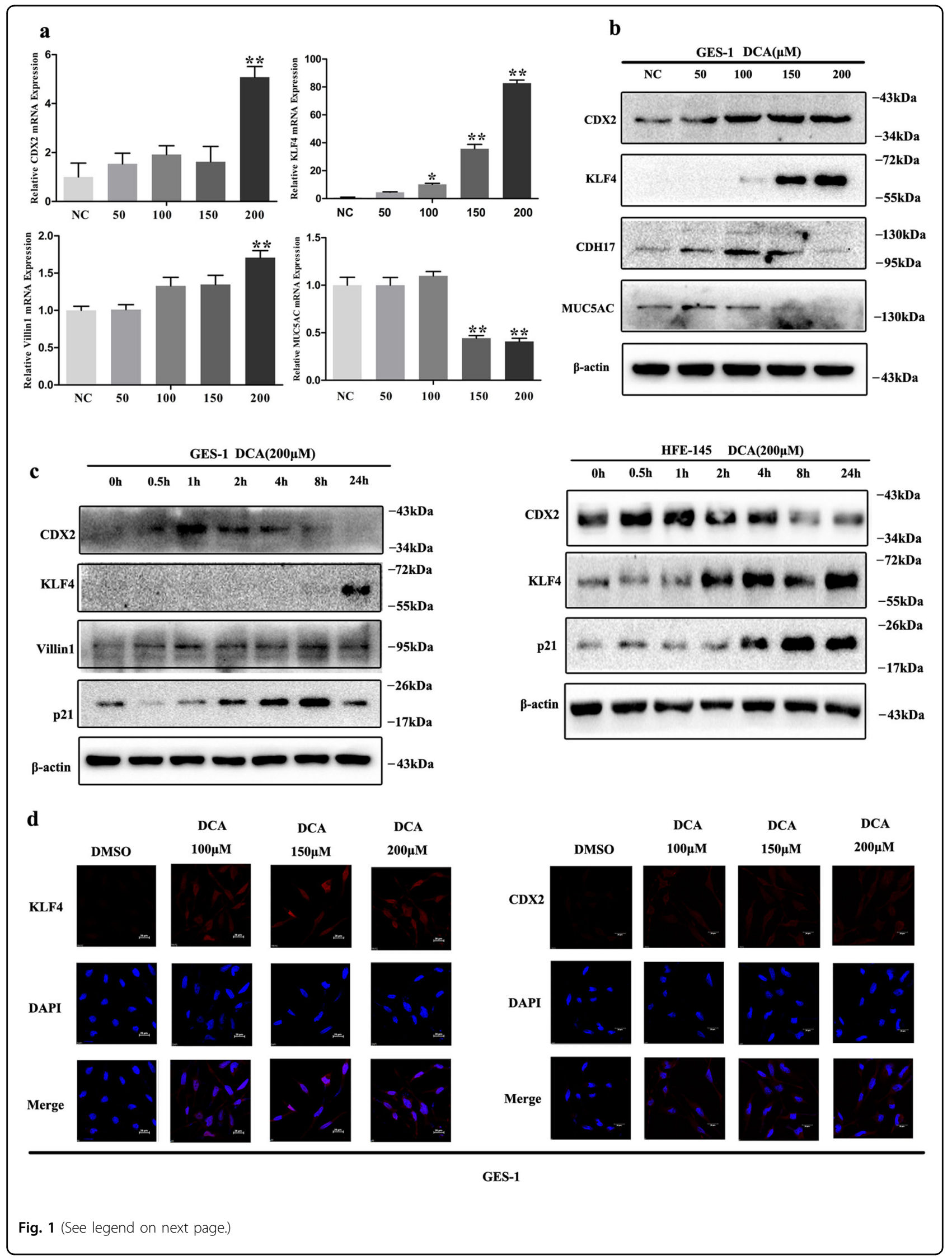


(see figure on previous page)

Fig. 1 Deoxycholic acid (DCA) treatment induced metaplasia markers expression in gastric epithelial cells. $\mathbf{a}$, $\mathbf{b}$ GES-1 cells were treated with different doses of DCA for $24 \mathrm{~h}$. Next, CDX2, KLF4, Villin1, and MUC5AC mRNA were detected by qRT-PCR. Error bar indicates the SEM, ${ }^{*} P<0.05$, ${ }^{* *} P<$ 0.01 vs. negative control (NC), $n=3$. CDX2, KLF4, CDH17, and MUC5AC proteins were detected by western blotting (WB). c GES-1 (upper) and HFE145 (lower) cells were treated with 200 MM DCA in a time-dependent manner. Columnar genes (CDX2, KLF4, Villin1, and p21) were examined by WB. d GES-1 cells were treated with $200 \mu \mathrm{M}$ DCA for $24 \mathrm{~h}$. KLF4 (left) and CDX2 (right) expression was analyzed by immunofluorescent staining (red). Nucleus was stained with DAPI (blue). Scale bar, $20 \mu \mathrm{m}$.

a

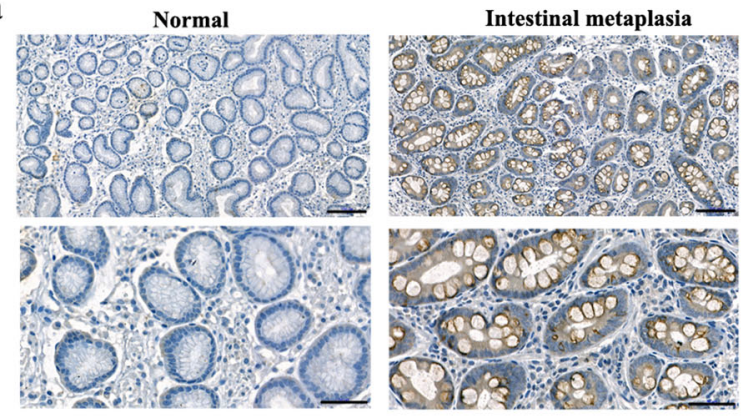

b

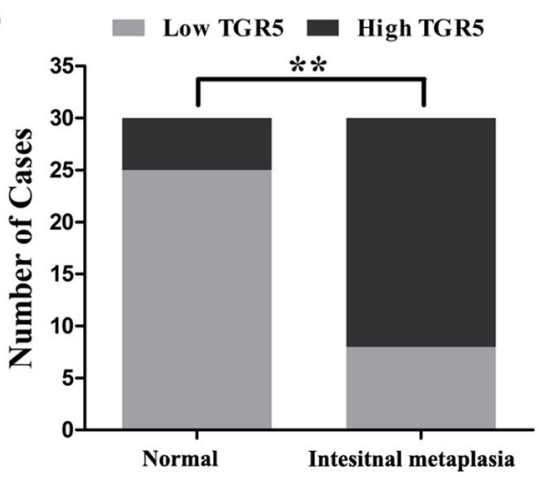

c

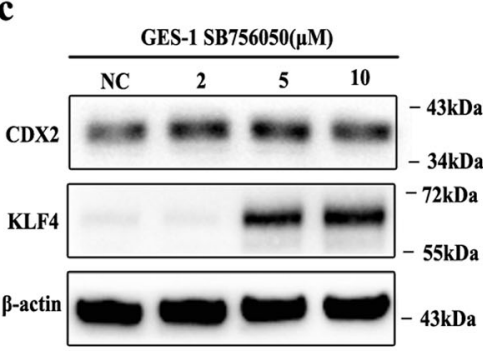

d

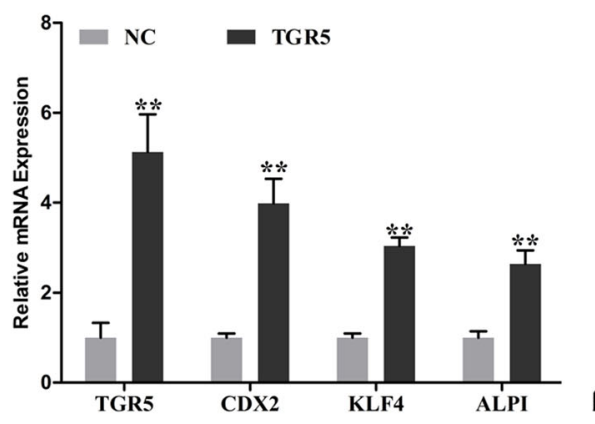

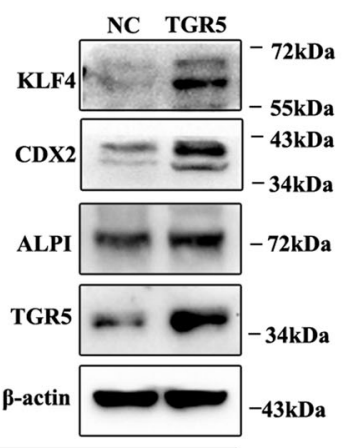

GES-1 e

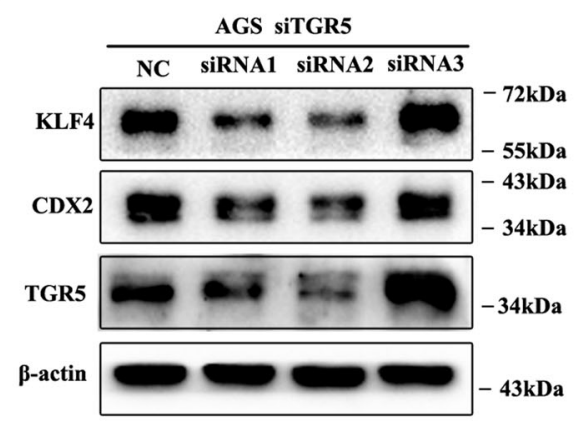

\section{f}

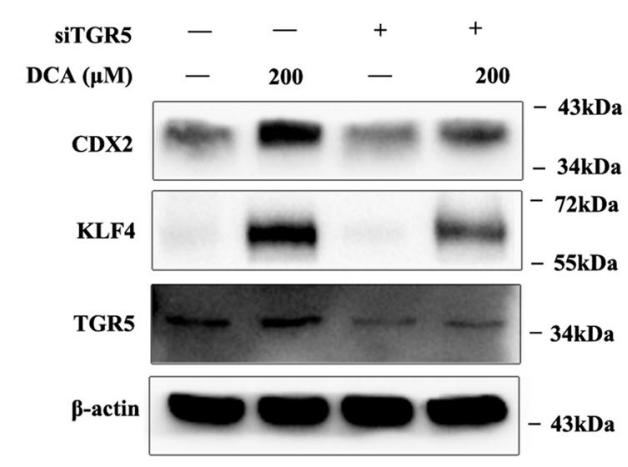

GES-1

Fig. 2 TGR5 was involved in gastric intestinal metaplasia (IM) development. a Immunohistochemical staining of normal and IM tissues showing TGR5 expression. Scale bar, $100 \mu \mathrm{m}$ (upper) and $50 \mu \mathrm{m}$ (lower). b Column charts showed the cases with high and low TGR5 expression in IM tissues. ${ }^{*} P<0.01$. c GES-1 cells were treated with SB756050 (2, 5, and $\left.10 \mu \mathrm{M}\right)$ for $24 \mathrm{~h}$. Then, KLF4 and CDX2 protein expression was examined by WB. d GES-1 cells were transfected with TGR5 overexpression lentiviral. TGR5, KLF4, CDX2, and ALPI mRNA and protein levels were analyzed by qRT-PCR and WB. Error bar indicates the SEM, ${ }^{* *} P<0.01$ vs. NC, $n=3$. e AGS cells were transfected with siRNAs target TGR5 for $72 \mathrm{~h}$. Then TGR5, KLF4, and CDX2 protein expressions were examined by WB. f Further, TGR5 was knocked down by transfection with siRNA in GES-1 cells. Next, the cells were treated with DCA $(200 \mu \mathrm{M})$ for $24 \mathrm{~h}$. TGR5, KLF4, and CDX2 were examined by WB. 


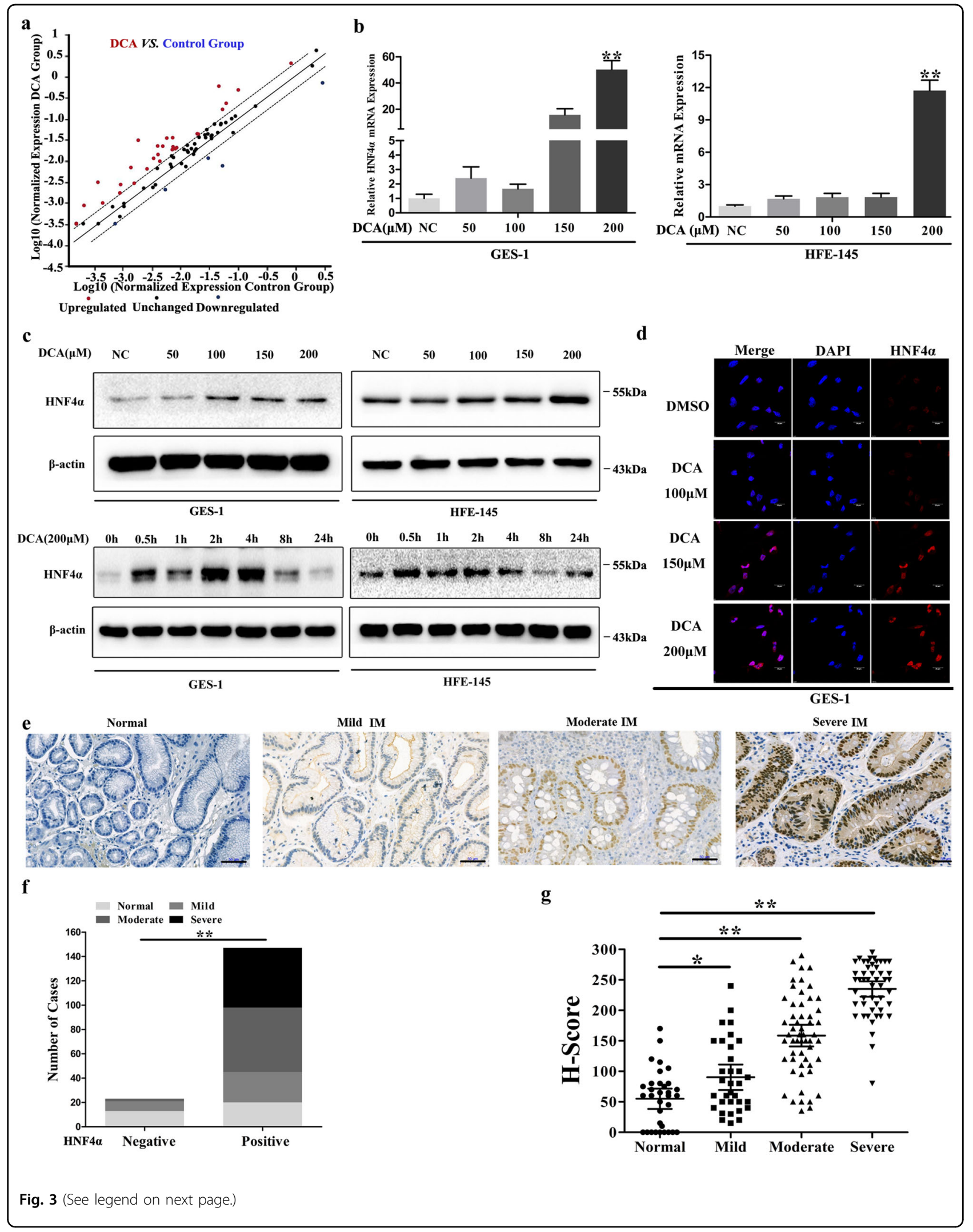


(see figure on previous page)

Fig. 3 Transcription factors profiling identified HNF4a as a key mediator after DCA exposure. a GES-1 cells were treated with $200 \mu \mathrm{M}$ DCA for $24 \mathrm{~h}$ and transcription factor (TF) expression profiles were examined using PCR array. Dots indicated genes over-expressed (red) and under-expressed (blue) ( $\geq 2.0$ fold) in DCA group vs. Control Group. b GES-1 and HFE-145 cells were treated with different doses of DCA for $24 \mathrm{~h}$. HNF4a mRNA levels were examined by qRT-PCR. Error bars indicate the SEM. ${ }^{* *} P<0.01$ vs. negative control (NC), $n=3$. c GES-1 (left) and HFE-145 (right) cells were treated with DCA in dose- and time-dependent manners. HNF4a protein levels were examined by western blotting. $\mathbf{d}$ GES-1 cells were treated with $200 \mu \mathrm{M}$ DCA for $24 \mathrm{~h}$. HNF4a expression was analyzed by immunofluorescent staining (red). Nucleus was stained with DAPI (blue). Scale bar, $20 \mu \mathrm{m}$. e Immunohistochemical (IHC) staining of normal and IM tissues showed HNF4a expression. Scale bar, $50 \mu \mathrm{m}$. $\mathbf{f}$ Column charts showed the cases with positive and negative HNF4a expression in normal and IM tissues. ${ }^{* *} P<0.01 . \mathbf{g ~ H}$-scores of HNF4a staining in normal and IM tissues (right). ${ }^{*} P<0.05$, ${ }^{* *} P<0.01$ vs. normal.

enriched including HNF4 $\alpha$, HNF1 $\alpha$, FOXA2, and PAX6 (Supplementary Fig. S2a). We also used GeneMANIA (https://genemania.org) to visualize the gene networks identified as being enriched (Supplementary Fig. S2b). Accordingly, we focused on HNF $4 \alpha$ ( $\geq 2.53$ vs. control), as previous studies revealed that HNF4 $\alpha$ was a pivotal TF in intestine differentiation ${ }^{25}$.

Then we examined HNF4 $\alpha$ expression levels in seven gastric epithelial cell lines by WB and qRT-PCR (Supplementary Fig. S1a, b). Next, both GES-1 and HFE-145 cells were treated with different doses of DCA $(0,50,100$, 150 , and $200 \mu \mathrm{M})$ for $24 \mathrm{~h}$. Both PCR and WB results showed a dose-dependent increase in HNF4 $\alpha$ mRNA and protein levels with reaching a maximum at $200 \mu \mathrm{M}$ (Fig. 3b, c). To further evaluate the DCA-induced kinetic changes in HNF4 $\alpha$ expression, GES-1 and HFE-145 cells were stimulated with $200 \mu \mathrm{M}$ DCA, and the HNF4 $\alpha$ protein levels at the indicated time points $(0.5,1,2,4,8$, and $24 \mathrm{~h}$ ) were determined by WB. As shown in Fig. 3c, $\mathrm{HNF} 4 \alpha$ expression increased at as early as $0.5 \mathrm{~h}$ following DCA treatment in both GES-1 and HFE-145 cell lines. IF results further revealed HNF4 $\alpha$ upregulation in the GES-1 cell nucleus treated with DCA $(200 \mu \mathrm{M})$ (Fig. 3d). These results clearly demonstrate that DCA exposure efficiently and quickly induces the transcription of HNF4 $\alpha$.

To further determine the effects of BAs on HNF4 $\alpha$ activation, a HNF4 TRE clone (Supplementary Fig. S2c) was transfected into GES-1 cells following DCA $(200 \mu \mathrm{M})$ treatment for $24 \mathrm{~h}$. Remarkably, luciferase activity was induced by nearly twofold compared with negative control (Supplementary Fig. S2d). These results demonstrate that DCA treatment not only increases HNF4 $\alpha$ expression but also induces HNF4 $\alpha$ transcriptional activity.

We then detected the expression pattern of HNF4 $\alpha$ using endoscopic biopsy specimens in normal and IM tissues by IHC (Fig. 3e). The positive rates of HNF4 $\alpha$ staining in normal, mild, moderate, and severe IM specimens were $57.6 \%, 63.6 \%, 92.7 \%$, and $100 \%$, respectively $(P<0.01)$ (Fig. 3f). The $\mathrm{H}$-score progressively increased from $55.0 \pm 8.1$ in normal specimens to $235.0 \pm 6.3$ in severe IM specimens $(P<0.01)$ (Fig. $3 g)$. We next detected the expression patterns of both P1- and P2-HNF4 $\alpha$ using gastric tissue microarrays (ST8017a and ST806) including
52 gastritis and 86 IM tissues (Supplementary Fig. S2e). The results indicated that the $\mathrm{H}$-score of $\mathrm{P} 1-\mathrm{HNF} 4 \alpha$ staining in IM tissues was significantly higher than that in gastritis tissues $(106.2 \pm 9.3$ vs. $20.6 \pm 4.9, P<0.01)$ (Supplementary Fig. S2f). In addition, the $\mathrm{H}$-score of P2$H N F 4 \alpha$ in IM tissues was higher than that in gastritis tissues, although no significant difference was noted $(P>$ 0.05) (Supplementary Fig. S2f). No significant differences were observed in the $\mathrm{H}$-score between P1-HNF4 $\alpha$ and P2HNF4 $\alpha$ in IM tissues $(P>0.05)$ (Supplementary Fig. S2f). These results reveal that both P1- and P2-HNF4 $\alpha$ expressions are increased during IM progression, with P1HNF4 $\alpha$ showing a larger increase.

\section{TGR5-ERK1/2 pathway was required for DCA-induced HNF4a and subsequent metaplasia markers expression}

To examine whether TGR5-mediated DCA induced HNF4 $\alpha$, GES-1, and HFE-145, cells were treated with TGR5 agonist (SB756050) for 24 $\mathrm{h}$. We found that HNF4 $\alpha$ expression was dramatically induced (Fig. 4a). Then GES1 cells were transfected with TGR5 overexpression lentivirus and significant increased HNF4 $\alpha$ mRNA and protein expression were observed (Fig. 4b). Next, AGS cells were transfected with siRNA against TGR5 for $72 \mathrm{~h}$, revealing that $\mathrm{HNF} 4 \alpha$ mRNA and protein expression were significantly repressed (Fig. 4c).

Previous researches demonstrated that TGR5 could positively regulate mitogen-activated protein kinase (MAPK), PI3K/Akt, and JAK/STAT pathways, and negatively regulate NF- $\mathrm{KB}$, both in physiological and pathological conditions ${ }^{23}$. To determine the pathway-mediated DCA-TGR5 effects, we first treated GES-1 cells with DCA in a dose-dependent manner. Results showed that DCA could significantly induce ERK1/2, p38 MAPK, and PI3K/ Akt pathways (Fig. 5a). Then, GES-1 cells were pretreated with ERK1/2 inhibitor U0126 $(10 \mu \mathrm{M})$, p38 MAPK inhibitor SB239063 $(10 \mu \mathrm{M})$, and PI3K/Akt inhibitor MK2206 $(10 \mu \mathrm{M})$ for $1 \mathrm{~h}$ before DCA treatment. Results indicated that U0126 could reverse HNF4 $\alpha$ expression induced by DCA exposure (Fig. 5b). In addition, pretreatment with U0126 could also significantly block DCA induced pERK1/2, KLF4, and CDX2 expression (Fig. 5c). Furthermore, TGR5 overexpression in GES-1 cells could 
Table 3 Significant changing transcription factors in DCA-treated GES-1 cell line.

\begin{tabular}{|c|c|c|}
\hline Gene symbol & Fold & Description \\
\hline ATF3 & 6.27 & Activating transcription factor 3 \\
\hline ATF4 & 4.73 & Activating transcription factor 4 \\
\hline CEBPA & 4.7 & CCAAT enhancer binding protein-a \\
\hline$C E B P B$ & 5.07 & CCAAT enhancer binding protein- $\beta$ \\
\hline CEBPG & 5.99 & CCAAT enhancer binding protein- $\gamma$ \\
\hline E2F1 & 2.54 & E2F transcription factor 1 \\
\hline E2F6 & 2.69 & E2F transcription factor 6 \\
\hline EGR1 & 5.49 & Early growth response 1 \\
\hline ELK1 & 2.06 & ETS transcription factor ELK1 \\
\hline ESR1 & 2.42 & Estrogen receptor 1 \\
\hline FOS & 3.31 & Fos proto-oncogene \\
\hline FOXA2 & 2.42 & Forkhead box A2 \\
\hline FOXG1 & 2.42 & Forkhead box G1 \\
\hline GATA1 & 2.42 & GATA-binding protein 1 \\
\hline GATA3 & 2.42 & GATA-binding protein 3 \\
\hline GTF2B & 2.19 & General transcription factor IIB \\
\hline HAND1 & 2.42 & Heart and neural crest derivatives expressed 1 \\
\hline HNF1A & 2.42 & HNF1 homeobox A \\
\hline HNF4A & 2.53 & Hepatocyte nuclear factor $4 a$ \\
\hline HSF1 & 2.53 & Heat shock transcription factor 1 \\
\hline IRF1 & 3.71 & Interferon regulatory factor 1 \\
\hline$J U N B$ & 2.19 & JunB proto-oncogene \\
\hline MAX & 2.34 & MYC-associated factor $X$ \\
\hline MEF2A & 3.08 & Myocyte enhancer factor $2 \mathrm{~A}$ \\
\hline MEF2C & 2.42 & Myocyte enhancer factor $2 \mathrm{C}$ \\
\hline MYC & 3.74 & MYC proto-oncogene, bHLH transcription factor \\
\hline MYF5 & 2.42 & Myogenic factor 5 \\
\hline MYOD1 & 2.42 & Myogenic differentiation 1 \\
\hline NFATC2 & 2.42 & Nuclear factor of activated T cells 2 \\
\hline NFKB1 & 2.4 & Nuclear factor-KB subunit 1 \\
\hline PAX6 & 2.42 & Paired box 6 \\
\hline POU2AF1 & 2.42 & POU class 2 homeobox associating factor 1 \\
\hline PPARA & 2.66 & Peroxisome proliferator activated receptor-a \\
\hline PPARG & 3.59 & Peroxisome proliferator activated receptor- $\gamma$ \\
\hline RELB & 9.33 & RELB proto-oncogene, NF-kB subunit \\
\hline SMAD1 & 17.72 & SMAD family member 1 \\
\hline STAT1 & 12.53 & Signal transducer and activator of transcription 1 \\
\hline STAT2 & 4.78 & Signal transducer and activator of transcription 2 \\
\hline TP53 & 3.13 & Tumor protein p53 \\
\hline$B 2 M$ & 2.37 & $\beta$-2-Microglobulin \\
\hline ID1 & -6.67 & Inhibitor of DNA binding 1, HLH protein \\
\hline SMAD9 & -2.41 & SMAD family member 9 \\
\hline TFAPZA & -2.48 & Transcription factor AP-2a \\
\hline ACTB & -4.34 & Actin- $\beta$ \\
\hline
\end{tabular}

DCA deoxycholic acid.

significantly promote $\mathrm{p}$-ERK1/2 expression (Fig. 4b). Lastly, we blocked TGR5 expression using siRNA and then treated GES- 1 cells with $200 \mu \mathrm{M}$ DCA for $24 \mathrm{~h}$. The results indicated that TGR5 silencing significantly alleviated $\mathrm{p}$-ERK1/2 and HNF4 $\alpha$ induction by DCA treatment (Fig. 5d). Together, these results indicate that TGR5 and following ERK1/2 pathway is involved in BA-induced $\mathrm{HNF} 4 \alpha$ and metaplasia markers expression.

\section{HNF4a-mediated DCA-induced columnar genes expression through directly regulating both KLF4 and CDX2}

Next, we manipulated HNF4 $\alpha$ expression using shRNA in AGS cells and found KLF4, CDX2, MUC13, and Villin1 mRNA and protein expression were all significantly suppressed (Fig. 6a). Furthermore, GES-1 cells were transfected with HNF4 $\alpha 2$ (Fig. 6b) and HNF4 $\alpha 8$ (Fig. 6c), respectively. Results showed that KLF4, CDX2, Villin1, and MUC13 were upregulated at the mRNA and protein levels after HNF4 $\alpha 2$ transfection (Fig. 6d). However, HNF4 $\alpha 8$ overexpression only increased ALPI mRNA and protein expression (Fig. 6c). KLF4, CDX2, Villin1, and MUC13 mRNA levels showed no significant differences (Fig. 6c). Then, we directly introduced HNF4 $\alpha 2$ in GES-1 cells and the IF results showed significant KLF4 and CDX2 upregulation (Supplementary Fig. S3a, b). These results indicate that both $\mathrm{P} 1$ - and $\mathrm{P} 2-\mathrm{HNF} 4 \alpha$ upregulation directly induce columnar genes expression in gastric epithelial cells in a non-redundant manner.

KLF4 have been demonstrated to be a gut-enriched TF, being involved in intestine development, goblet cells differentiation and maturation, and intestinal epithelial homeostasis $^{26}$. Our above results revealed that HNF4 $\alpha 2$ could transcriptionally regulate KLF4. Then, we examined the promoter of KLF4 and detected one putative HNF4binding site (Fig. 6d). Next, we performed luciferase reporter gene analysis and found that HNF4 22 could positively regulate KLF4 promoter activity covering the HNF4-binding site (Fig. 6d). ChIP assays further confirmed that HNF4 $\alpha$ bound to the speculative site on the KLF4 promoter in GES-1 cells after DCA treatment (Fig. 6e). Furthermore, we knocked down KLF4 expression in AGS cells and found that CDX2, MUC13, and ALPI mRNA and protein levels significantly decreased (Supplementary Fig. S4a, b), although no significant difference was noted on Villin1 mRNA (Supplementary Fig. S4a).

HNF4 $\alpha$ regulates CDX2 expression in both normal intestinal cells and during intestine carcinogenesis ${ }^{27,28}$. We next examined the promoter of CDX2 and detected five putative HNF4-binding sites. To determine the effects of HNF $4 \alpha$ on CDX2 promoter activities, we performed luciferase reporter gene analysis and found that HNF4 $\alpha 2$ activated the CDX2 promoters between $\sim 1510$ and $\sim 2000$ bp (Fig. 6f). Then we knocked down CDX2 in AGS cells and introduced CDX2 expression in GES-1 cells. The WB results indicated that CDX2 positively regulated KLF4 and Villin1 expression (Supplementary Fig. S4c, d).

Next, to determine the effects of HNF4 $\alpha$ in DCAinduced columnar genes expression, we initially treated AGS and BGC823 cell lines (both with relatively high HNF4 $\alpha$ expression) with BI6015, an antagonist of 
a

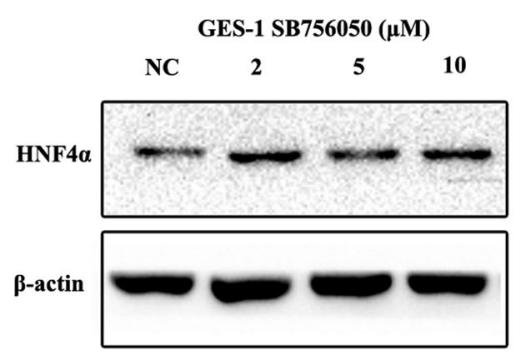

b

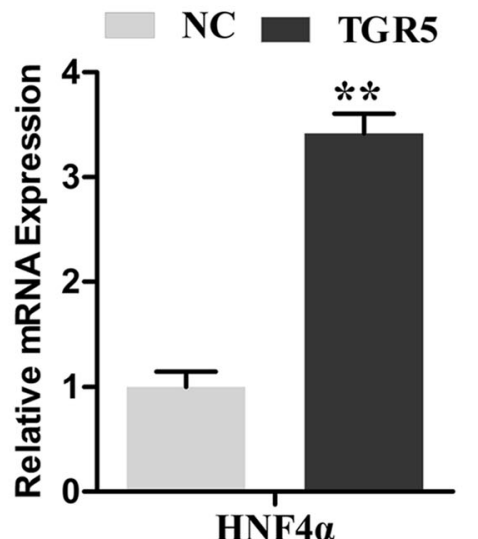

HNF4a

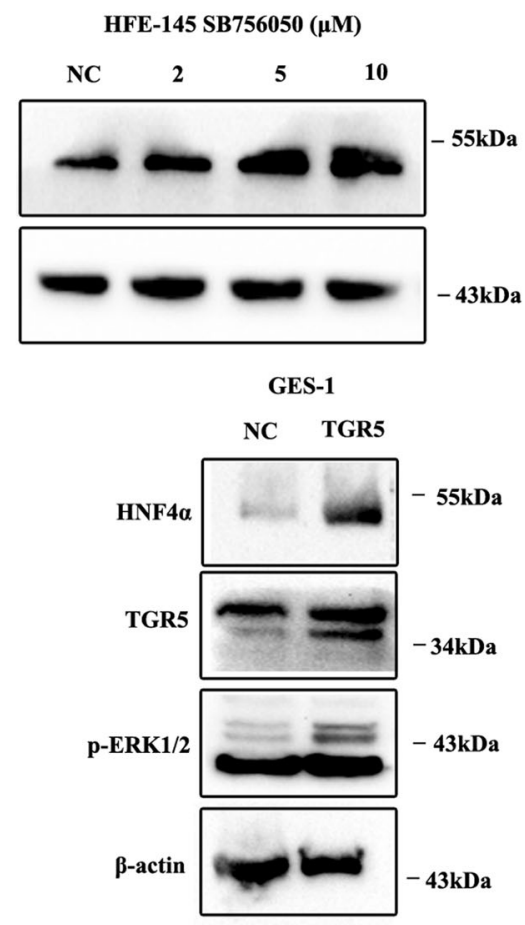

c
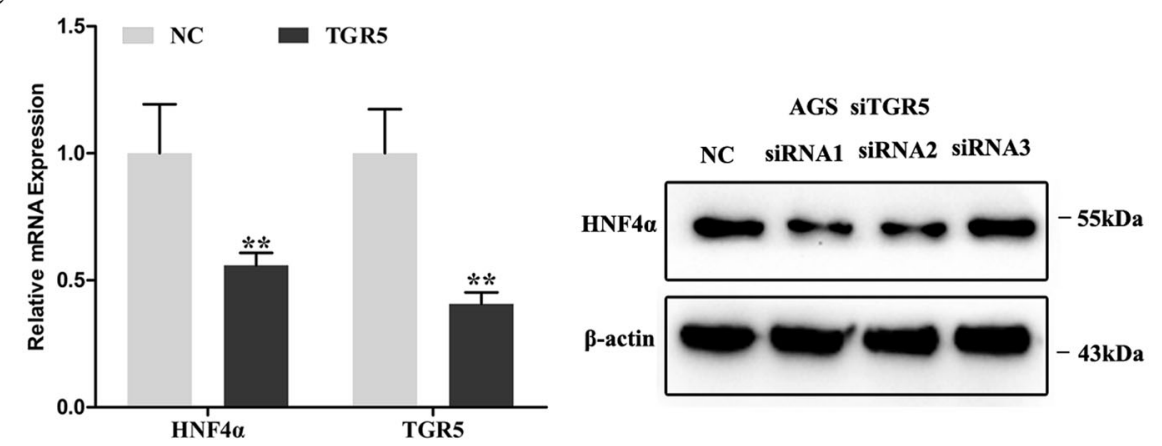

Fig. 4 TGR5-mediated bile acids induced HNF4a and columnar genes expression. a GES-1 and HFE-145 cells were treated with SB756050 (2, 5, and $10 \mu \mathrm{M}$ ) for $24 \mathrm{~h}$. Then, HNF4a protein expression was detected by western blotting (WB). b GES-1 cells were transfected with TGR5 overexpression lentivirus. HNF4a mRNA expression were examined by qRT-PCR. Error bar indicates the SEM, ${ }^{* *} P<0.01 \mathrm{vs}$. negative control (NC), $n=$ 3. TGR5, p-ERK1/2, and HNF4a protein expression were examined by WB. c AGS cells were transiently transfected with siRNA against TGR5. TGR5 and HNF4a mRNA was examined by qRT-PCR. Error bar indicates the SEM, ${ }^{* *} P<0.01 \mathrm{VS}$. NC, $n=3$. HNF4a protein expression was examined by WB.

$\mathrm{HNF} 4 \alpha^{29}$, for $24 \mathrm{~h}$ and columnar genes expression were examined using WB. The results revealed that BI6015 treatment $(1,2,5,10$, and $20 \mu \mathrm{M})$ significantly inhibited KLF4, CDX2, ALPI, CDH17, and Villin1 expression in a dose-dependent manner (Fig. 7a, b). Next, GES-1 cells were pretreated with BI6015 for $1 \mathrm{~h}$ and then treated with $200 \mu \mathrm{M}$ DCA for $24 \mathrm{~h}$. As expected, pretreatment with BI6015 at 2, 5, and $10 \mu \mathrm{M}$ reversed DCA-induced KLF4, CDX2, ALPI, and Villin1 expression (Fig. 7c). Lastly, GES1 cells were successfully transfected with shHNF4 $\alpha$ lentiviral and then treated with $200 \mu \mathrm{M}$ DCA for $24 \mathrm{~h}$. The WB results showed that HNF $4 \alpha$ knockdown completely blocked DCA-induced metaplasia markers expression in a similar manner as BI6015 (Fig. 7d).

\section{Correlation between TGR5 and HNF4a/CDX2/KLF4 in gastric IM tissues}

To further confirm the relationship between TGR5 and metaplasia markers in IM, we detected TGR5, HNF4 $\alpha$, CDX2, and KLF4 expression using three consecutive 


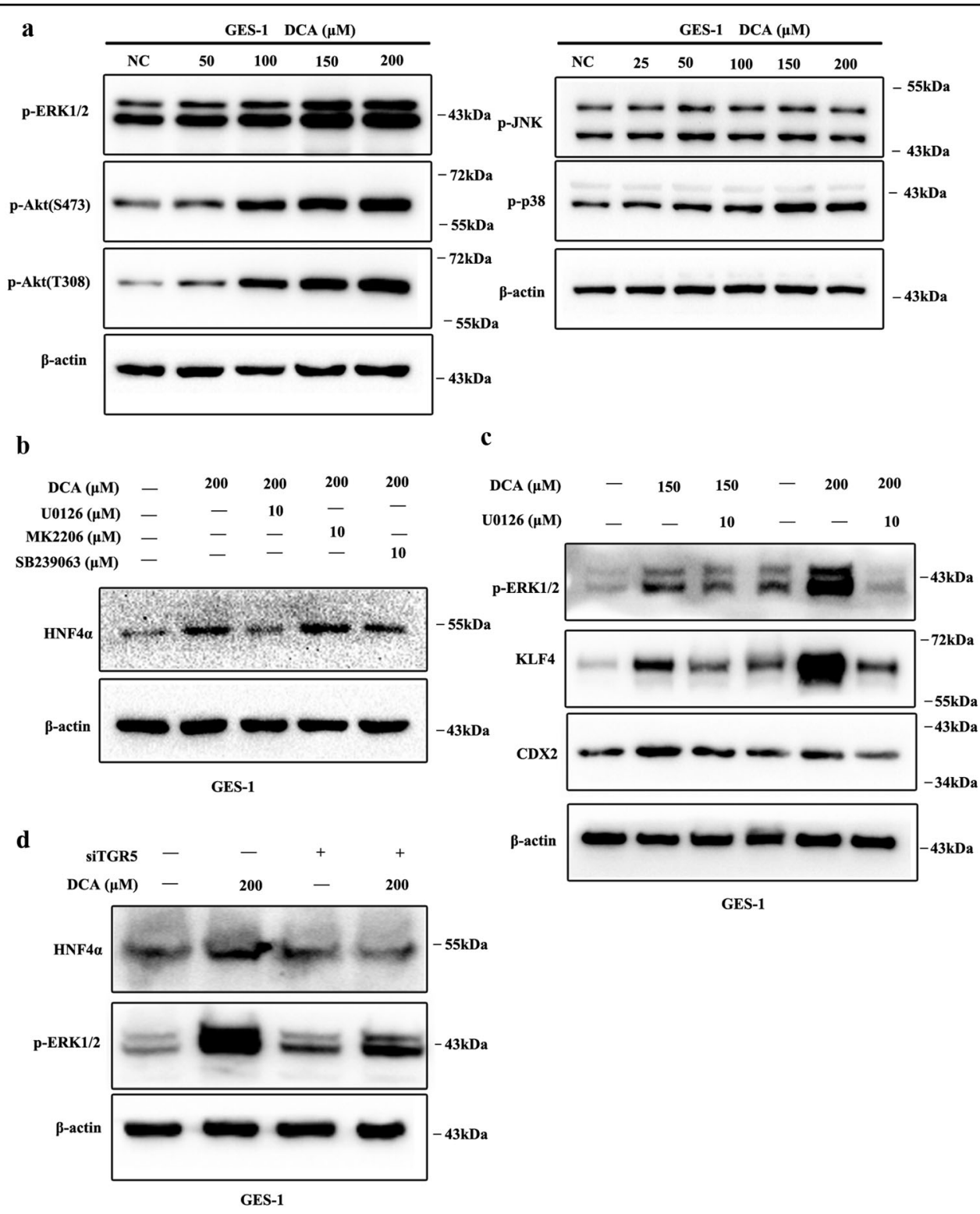

Fig. 5 ERK1/2 pathway was involved in DCA-TGR- induced HNF4a and following metaplasia markers expression. a GES-1 cells were treated with DCA $(0,25,50,100,150$, and $200 \mu \mathrm{M})$ for $24 \mathrm{~h}$. Then, MAPK and PI3K/Akt pathways were examined by WB. b GES-1 cells were pretreated with

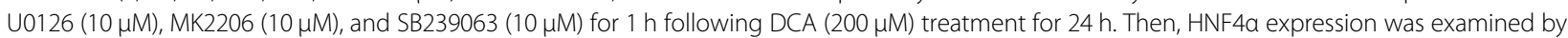

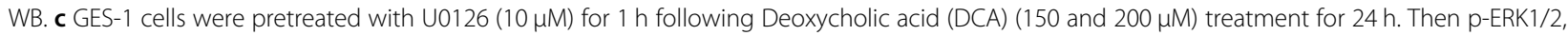
KLF4, and CDX2 proteins expression were examined by western blotting. d Further, TGR5 was knocked down by transfection with siRNA in GES-1 cells. Next, the cells were treated with DCA $(200 \mu \mathrm{M})$ for $24 \mathrm{~h}$. p-ERK1/2 and HNF4a were examined by WB.

slides of gastric tissue including 120 cases IM and 67 cases of chronic superficial gastritis by IHC (Fig. 8a). The Hscores of HNF4 $\alpha$, CDX2, and KLF4 protein were $33.0 \pm$ 7.6 vs. $122.1 \pm 8.3(P<0.01), 17.0 \pm 5.6$ vs. $60.4 \pm 5.9(P<$ $0.01)$, and $58.8 \pm 7.3$ vs. $129.7 \pm 6.5(P<0.01)$ in gastritis vs. IM tissues, respectively (Fig. $8 \mathrm{~b}$ ). In addition, the expression of HNF4 $\alpha$, CDX2, and KLF4 was positively correlated with each other $(P<0.05$, Fig. $8 \mathrm{c})$. Moreover, the H-score of HNF4 $\alpha$, KLF4, and CDX2 in high TGR5 cases was significantly higher than in low TGR5 cases in IM tissues (Fig. $8 \mathrm{~d}, P<0.01$ ). These results indicate that HNF4 $\alpha /$ KLF4/CDX2 expressions are synchronously increased with TGR5 during IM progression.

\section{Discussion}

Herein, we demonstrated that BAs receptor TGR5 was significantly increased in IM tissues and promoted metaplasia markers expression in gastric epithelial cells. 

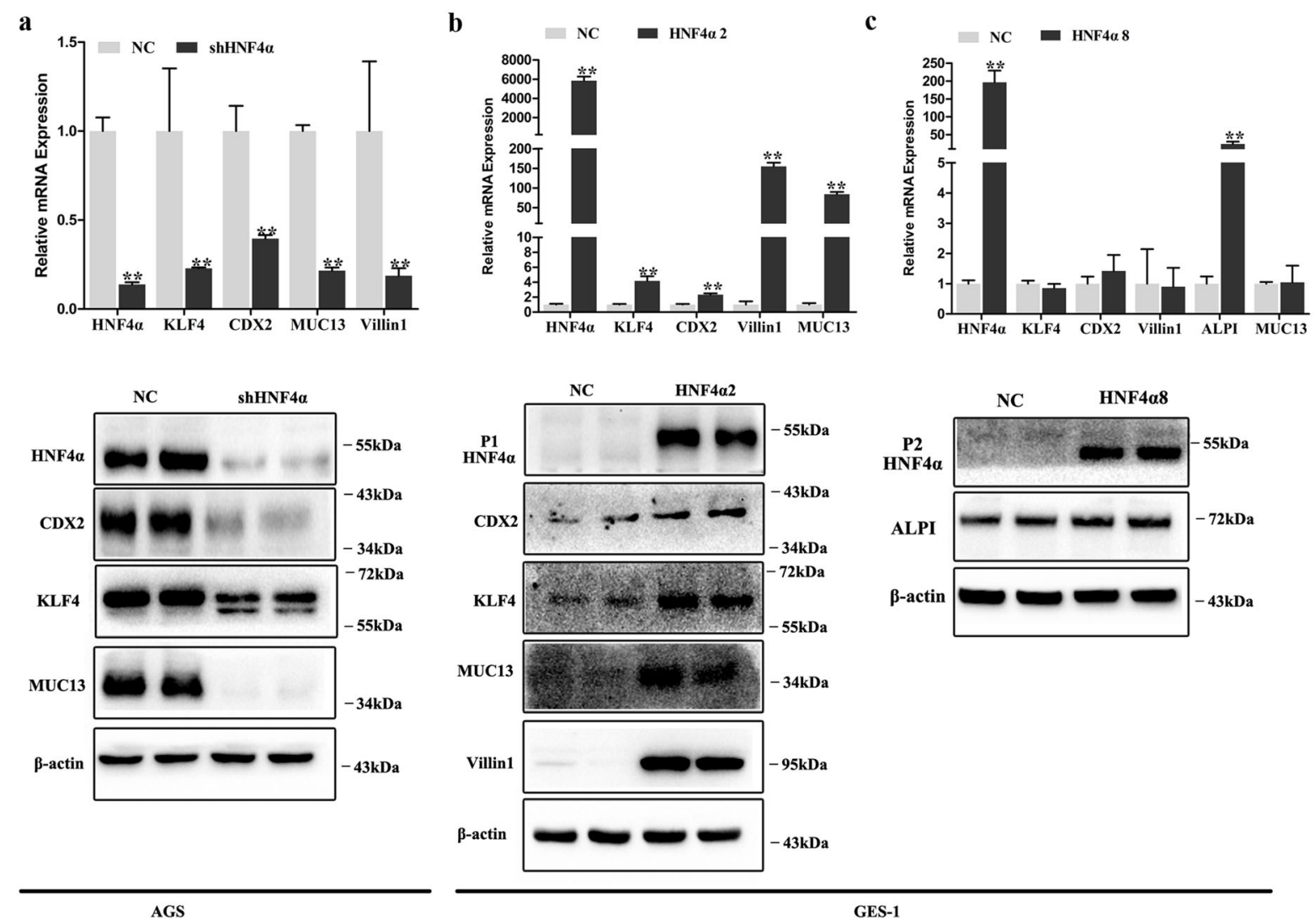

d

$\mathbf{e}$
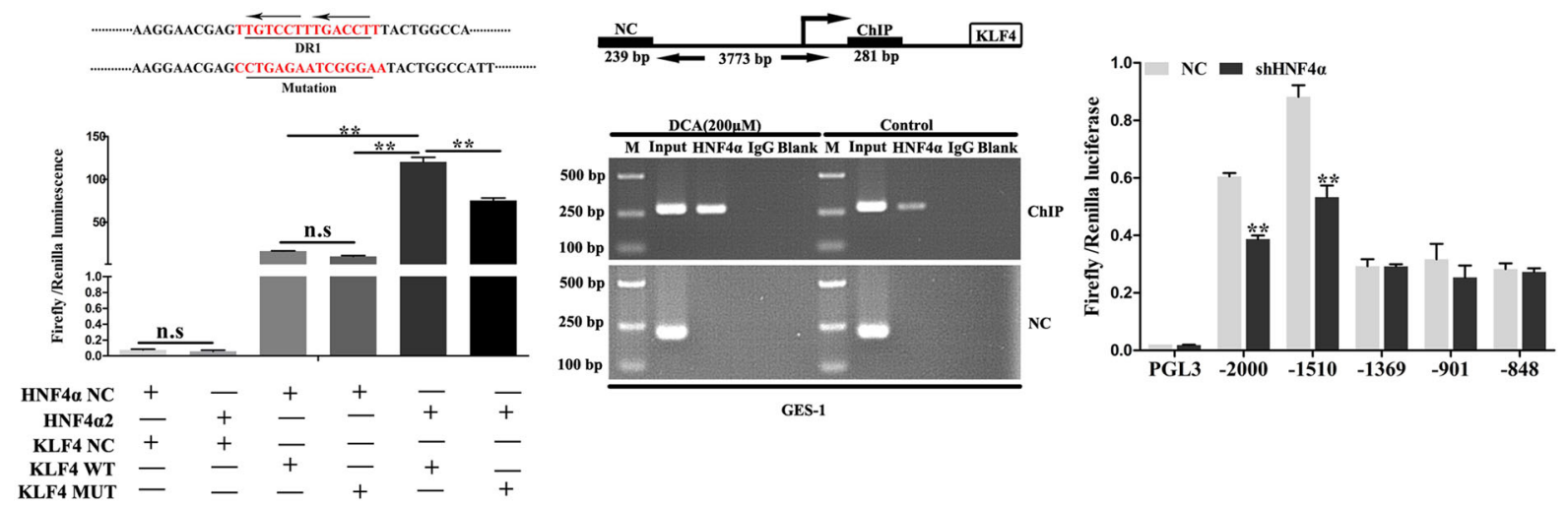

Fig. 6 HNF4a transcriptionally regulated KLF4 and CDX2 in gastric epithelial cells. a AGS cells were transfected with shRNA lentiviral target HNF4a. Next, P1-HNF4a, P2-HNF4a, CDX2, KLF4, Villin1, and MUC13 were analyzed by western blotting (WB) and qRT-PCR. Error bar indicates the SEM, ${ }^{*} P<0.01$ vs. negative control (NC), $n=3$. b GES-1 cells were transfected with HNF4a2 overexpression lentiviral. HNF4a, KLF4, CDX2, MUC13, and Villin1 expression were analyzed by qRT-PCR and WB. Error bar indicates the SEM, ${ }^{* *} P<0.01 \mathrm{vs.} \mathrm{NC,} n=3$. c GES-1 cells were transfected with HNF4a8 overexpression lentiviral. HNF4a, KLF4, CDX2, MUC13, Villin1, and ALPI mRNA was analyzed by qRT-PCR. Error bar indicates the SEM, ${ }^{* *} P<0.01$ vs. NC, $n=3$. ALPI protein level was analyzed by WB. d KLF4 promoter fragment (2000 bp) from Ensemble was predicated using JASPAR tool. Reporter constructs containing the predicted HNF4-binding site and mutational site are shown (upper). Negative control (NC) and HNF4a2 overexpression plasmid was transiently transfected with these KLF4 promoter reporter constructs for $24 \mathrm{~h}$ and luciferase activity was assayed thereafter (lower). KLF4 promoter activity was expressed as fold induction (means \pm SEM) compared with that of $\mathrm{NC}, n=3 .{ }^{*} P<0.01$. e GES-1 cells were treated with DCA $(200 \mu \mathrm{M})$ for $24 \mathrm{~h}$. Then, ChIP assay was performed to demonstrate the direct binding of HNF4a to the KLF4 promoter. DCA, Deoxycholic acid; M, Marker. $\mathbf{f}$ shHNF4a stably transfected AGS cells were transiently transfected with CDX2 promoter reporter constructs containing the predicted HNF4binding sites for $24 \mathrm{~h}$ and luciferase activity was assayed. CDX2 promoter activity was expressed as the fold induction (means \pm SEM) compared with that of $N C .{ }^{*} P<0.01, n=3$. 


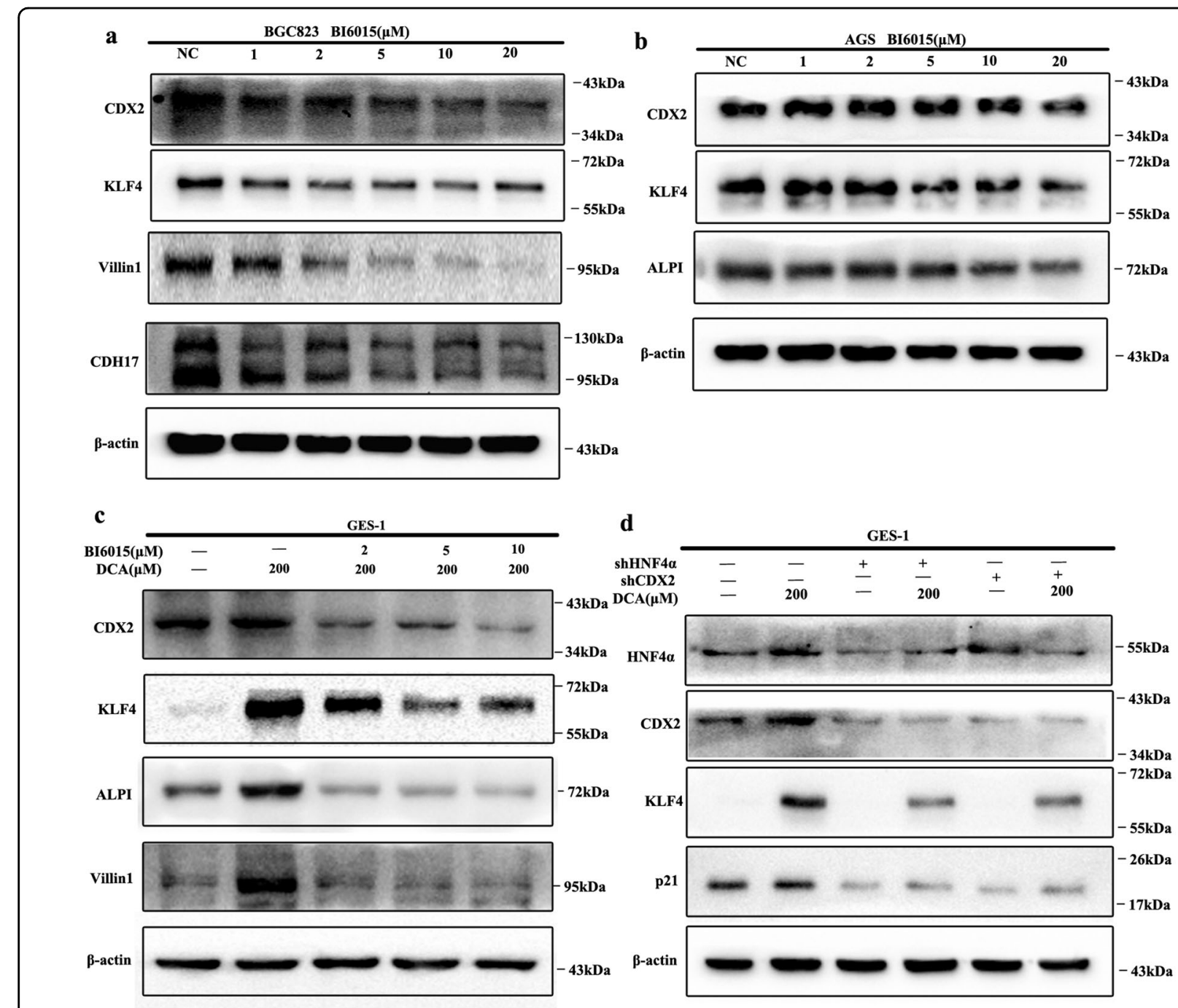

Fig. 7 HNF4a-mediated bile acids induced columnar genes expression. $\mathbf{a}, \mathbf{b}$ BGC823 cells (a) and AGS cells (b) were treated with different doses of Bl6015 for 24 h. CDX2, KLF4, Villin1, CDH17, and ALPI expression was examined by western blot (WB). c GES-1 cells were pretreated with Bl6015 (2, 5, and $10 \mu \mathrm{M})$ for $1 \mathrm{~h}$ and then treated with DCA $(200 \mu \mathrm{M})$ for another $24 \mathrm{~h}$. KLF4, CDX2, ALPI, and Villin1 expression was detected by WB. $\mathbf{d}$ HNF4a and CDX2 were knocked down by stable transfection with shRNA lentiviral in GES-1 cells. Next, the cells were treated with DCA (200 $\mu \mathrm{M})$ for $24 \mathrm{~h}$. HNF4a, CDX2, KLF4, and p21 were examined by WB.

Furthermore, we identified that HNF4 $\alpha$-mediated DCATGR5 induced metaplasia markers expression through directly regulating both KLF4 and CDX2 promoter activities. Mechanically, ERK1/2 pathway was involved in DCA-TGR5-induced HNF4 $\alpha$ and following metaplasia markers expression.

Molecular changes involved in IM are theoretically recapitulated from the intestine development. Accordingly, key pathways including Wnt, fibroblast growth factor, BMP, Hedgehog, and Notch are involved in Barrett's esophagus (BE) and IM development ${ }^{30,31}$. In addition, the pivotal TFs involved in intestinal epithelium morphogenesis and differentiation, such as CDX1/ 2, SOX9, Math1, PDX1, and GATA4/6 are important in
IM initiation and evolution through regulating intestine differentiation genes ${ }^{32}$. Intestinal stem cells show stomach features after CDX2 knockdown ${ }^{33}$. KLF4 is a zincfinger $\mathrm{TF}$ primarily in post-mitotic, terminally differentiated epithelial cells in gastrointestinal tract ${ }^{26}$. $\mathrm{KLF}^{-1-}$ mice show a dramatical decrease in goblet cell number and abnormal goblet cell morphology ${ }^{34}$. Although the key roles of CDX2 and KLF4 in metaplasia process have been reported, the underlying mechanism remains unclear.

DGR has been identified as a key risk factor for GC development ${ }^{35}$. In addition, higher concentrations of DCA $(400 \mu \mathrm{M})$ could promote gastric cells apoptosis ${ }^{36}$ and $200 \mu \mathrm{M}$ was used to examine $\mathrm{IM}^{37}$. The nuclear 


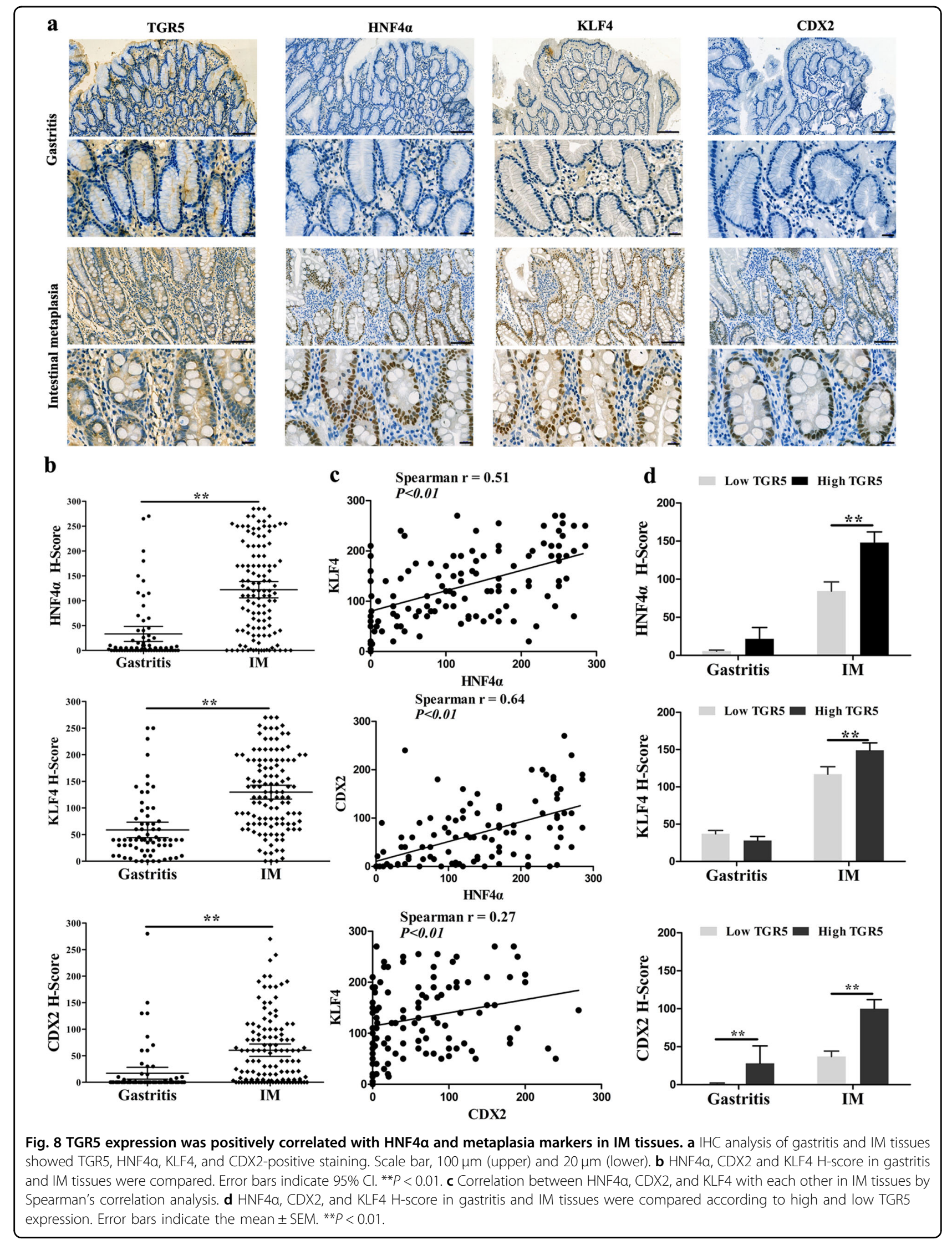


receptor farnesoid X receptor (FXR) and G-proteincoupled receptor TGR5 mediate the effects of $\mathrm{BAs} \mathrm{s}^{23,38}$. Our previous study showed that primary BAs (CDCA) could promote CDX2 expression through the FXR-SHP$\mathrm{NF}-\mathrm{KB}^{16}$ and FXR-miR-92a-FOXD1-NF- $\mathrm{KB}^{10}$ signaling pathways. However, the functions of TGR5 in IM have not been fully clarified. TGR 5 has been demonstrated to be involved in immune, inflammation, and metabolic disorders $^{23}$. Guo et al. ${ }^{39,40}$ previously showed that TGR5 could suppress gastric inflammation and GC cells proliferation through inhibiting NF-KB and STAT3 pathway. In contrast, Cao et $\mathrm{al}^{41}$ demonstrated that TGR5 expression was increased in intestinal-type GC and mediated BA-induced GC cells proliferation. Here we clearly showed that, during gastric IM development, TGR5 expression was significantly increased and promoted columnar gene expression through ERK1/2 pathway. Thus, we speculated that the functions of TGR5 might be tissue-specific and was diverse due to different external stimulus. And upon BAs exposure, TGR5 contributes to IM development. We first demonstrated that TGR5 could positively regulate both KLF4 and CDX2 expression at transcriptional level upon BA treatment. Our results indicated that TGR5 might directly contribute to malignant transformation of gastric epithelial cells upon BAs exposure.

Next, we identified that HNF4 $\alpha$, a more broad TF that emerges earlier during gut development, was dramatically induced downstream DCA-TGR5 pathway. HNF4 $\alpha$ is a highly conserved nuclear receptor expressed in the gut, kidney, liver, and pancreas during early development ${ }^{42}$. The HNF4 $\alpha$ gene uses two separate promoters, P1 and P2, and is generated into $\alpha 1-\alpha 6$ and $\alpha 7-\alpha 9$, respectively, through alternative splicing ${ }^{43}$. Normal colon epithelial differentiation and goblet cell maturation are dependent on HNF4 $\alpha^{44}$. Moreover, HNF4 $\alpha$ is not expressed in the normal esophagus, but emerges in BE and directly induces the columnar phenotype in esophageal epithelial cells ${ }^{45,46}$. Importantly, increased HNF4 $\alpha$ expression was observed in gastric IM and intestinal-type adenocarcinomas ${ }^{47}$. In addition, a recent study revealed the feasibility of using HNF4 $\alpha$ as a therapeutic target in $\mathrm{GC}^{48}$. However, in these models, it remains unclear whether HNF4 $\alpha$ mediates gastric epithelial cell trans-differentiation in response to BAs exposure. Our results preliminary reveal that both P1- and P2-HNF4 $\alpha$ are involved in IM development in non-redundant manner. Interestingly, one recent study revealed that the HNF4 $\alpha$ isoforms splicing are involved in BE development ${ }^{49}$, with P1-HNF4 $\alpha$ increased significantly without P2-HNF4 $\alpha$ upregulation. Accordingly, the functions and distribution of P1- and P2-HNF4 $\alpha$ may widely vary during the development of different diseases ${ }^{50}$.

Mechanically, we found that HNF4 $\alpha$ could directly regulate KLF4 and CDX2 expression. Further, KLF4 and
CDX2 could regulate reciprocally and promote columnar genes expression, which was consistent with previous studies in both $\mathrm{BE}^{51}$ and $\mathrm{IM}^{52}$. Previous studies demonstrated that HNF4 $\alpha$ could directly regulate CDX2, both in intestine development and colorectal cancer ${ }^{27,28}$. However, recent studies using esophagus squamous cells and mouse embryonic fibroblasts revealed no notable CDX2 expression after HNF4 $\alpha$ introduction ${ }^{45,53}$. The discrepancy may be due to the different cell lines. In addition, HNF4 $\alpha$, KLF4, and CDX2 could positively regulate their own promoter activities ${ }^{51,54,55}$. Together with our results, this HNF4 $\alpha$ central network not only initiates the expression of IM-related genes in a synergetic manner, but also promotes IM persistence after pathogenic factor elimination.

In conclusion, we elucidated that BAs treatment could activate TGR5-ERK1/2 pathway following induction of HNF4 $\alpha$ expression, which further promoted metaplasia markers expression through direct regulation of KLF4 and CDX2. These results shed light that suppression TGR5HNF4 $\alpha$ signaling cascade maybe a potential therapeutic target for blocking Correa's cascade progression and GC development.

\section{Acknowledgements \\ This work was supported by Natural Science Foundation of China (Grant Numbers 81873554 and 81502009) and Shaanxi Foundation for Innovation Team of Science and Technology (Grant No. 2018TD-003).}

\section{Author details \\ 'State Key Laboratory of Cancer Biology and Institute of Digestive Diseases, Xijing Hospital, Fourth Military Medical University, Xi'an, Shaanxi 710032, China. ${ }^{2}$ Department of Gastroenterology, General Hospital of Western Theater Command, Chengdu, Sichuan 610083, China. ${ }^{3}$ Department of Gastroenterology, Second Affiliated Hospital of Xi'an Medical College, Xi'an Shaanxi 710038, China. ${ }^{4}$ Department of Endocrinology, General Hospital of Western Theater Command, Chengdu, Sichuan 610083, China. ${ }^{5}$ Department of Gastroenterology, 989 Hospital of the People's Liberation Army, Luoyang, Henan 471003, China. ${ }^{6}$ Department of Gastroenterology, First Affiliated Hospital of Zhengzhou University, Zhengzhou, Henan 450052, China. ${ }^{7}$ Department of Medicine and Cancer Center, Howard University, Washington, DC 20060, USA. ${ }^{8}$ Department of Internal Medicine, Meharry Medical College, Nashville, TN 37208, USA}

\section{Conflict of interest}

The authors declare that they have no conflict of interest.

\section{Publisher's note}

Springer Nature remains neutral with regard to jurisdictional claims in published maps and institutional affiliations.

The online version of this article (https://doi.org/10.1038/s41420-020-0290-3) contains supplementary material, which is available to authorized users.

Received: 19 March 2020 Revised: 18 May 2020 Accepted: 3 June 2020 Published online: 06 July 2020

\footnotetext{
References

1. Bray, F. et al. Global cancer statistics 2018: GLOBOCAN estimates of incidence and mortality worldwide for 36 cancers in 185 countries. CA Cancer J. Clin. $\mathbf{6 8}$, 394-424 (2018)
} 
2. Song, $\mathrm{H}$. et al. Incidence of gastric cancer among patients with gastric precancerous lesions: observational cohort study in a low risk Western population. BMJ 351, h3867 (2015).

3. Zhang, P. et al. Dissecting the single-cell transcriptome network underlying gastric premalignant lesions and early gastric cancer. Cell Rep. 27, 1934-1947 (2019).

4. Amieva, M. R. \& El Omar, E. M. Host-bacterial interactions in Helicobacter pylori infection. Gastroenterology 134, 306-323 (2008).

5. Chen, H., Wang, Z., Li, X. \& Zhou, Z. Helicobacter pylori eradication cannot reduce the risk of gastric cancer in patients with intestinal metaplasia and dysplasia: evidence from a meta-analysis. Gastric Cancer 19, 166-175 (2016).

6. Tatsugami, M. et al. Bile acid promotes intestinal metaplasia and gastric carcinogenesis. Cancer Epidemiol. Biomark. Prev. 21, 2101-2107 (2012).

7. Matsuhisa, T. et al. Relation between bile acid reflux into the stomach and the risk of atrophic gastritis and intestinal metaplasia: a multicenter study of 2283 cases. Dig. Endosc. 25, 519-525 (2013).

8. Nakamura, M. et al. Duodenogastric reflux is associated with antral metaplastic gastritis. Gastrointest. Endosc. 53, 53-59 (2001).

9. Dixon, M. F., Mapstone, N. P., Neville, P. M., Moayyedi, P. \& Axon, A. T. Bile reflux gastritis and intestinal metaplasia at the cardia. Gut 51, 351-355 (2002).

10. Li, T. et al. MicroRNA-92a-1-5p increases CDX2 by targeting FOXD1 in bile acids-induced gastric intestinal metaplasia. Gut 68, 1751-1763 (2019).

11. Barros, R., Freund, J., David, L. \& Almeida, R. Gastric intestinal metaplasia revisited: function and regulation of CDX2. Trends Mol. Med. 18, 555-563 (2012).

12. Flandez, M., Guilmeau, S., Blache, P. \& Augenlicht, L. H. KLF4 regulation in intestinal epithelial cell maturation. Exp. Cell Res. 314, 3712-3723 (2008).

13. Mutoh, H. et al. Cdx1 induced intestinal metaplasia in the transgenic mouse stomach: comparative study with Cdx2 transgenic mice. Gut 53, 1416-1423 (2004).

14. Silberg, D. G. et al. Cdx2 ectopic expression induces gastric intestinal metaplasia in transgenic mice. Gastroenterology 122, 689-696 (2002).

15. Sarkar, A. et al. Sox2 suppresses gastric tumorigenesis in mice. Cell Rep. 16, 1929-1941 (2016).

16. Zhou, H. et al. Activation of FXR promotes intestinal metaplasia of gastric cells via SHP-dependent upregulation of the expression of CDX2. Oncol. Lett. 15 7617-7624 (2018).

17. Yuan, T. et al. SOX2 interferes with the function of CDX2 in bile acid-induced gastric intestinal metaplasia. Cancer Cell Int. 19, 24 (2019).

18. Dixon, M. F., Genta, R. M., Yardley, J. H. \& Correa, P. Classification and grading of gastritis. The updated Sydney System. International Workshop on the Histopathology of Gastritis, Houston 1994. Am. J. Surg. Pathol. 20, 1161-1181 (1996)

19. Tang, X. D. et al. Randomized double-blind clinical trial of Moluodan () for the treatment of chronic atrophic gastritis with dysplasia. Chin. J. Integr. Med. 22, 9-18 (2016)

20. Zhang, Q. et al. Acidic bile salts induce epithelial to mesenchymal transition via VEGF signaling in non-neoplastic Barrett's cells. Gastroenterology 156, 130-144 (2019).

21. Liu, X. et al. The membrane bile acid receptor TGR5 drives cell growth and migration via activation of the JAK2/STAT3 signaling pathway in non-small cell lung cancer. Cancer Lett. 412, 194-207 (2018).

22. Gadacz, T. R. \& Zuidema, G. D. Bile acid composition in patients with and without symptoms of postoperative refulx gastritis. Am. J. Surg. 135, 48-52 (1978).

23. Guo, C., Chen, W. D. \& Wang, Y. D. TGR5, not only a metabolic regulator. Front Physiol. 7, 646 (2016).

24. Wang, J., Vasaikar, S., Shi, Z., Greer, M. \& Zhang, B. WebGestalt 2017: a more comprehensive, powerful, flexible and interactive gene set enrichment analysis toolkit. Nucleic Acids Res. 45, W130-W137 (2017).

25. Chen, L. et al. A reinforcing HNF4-SMAD4 feed-forward module stabilizes enterocyte identity. Nat. Genet 51, 777-785 (2019).

26. Ghaleb, A. M. \& Yang, V. W. Kruppel-like factor 4 (KLF4): What we currently know. Gene 611, 27-37 (2017).

27. Boyd, M., Bressendorff, S., Møller, J., Olsen, J. \& Troelsen, J. T. Mapping of HNF4a target genes in intestinal epithelial cells. BMC Gastroenterol. 9, 68 (2009).

28. Saandi, T. et al. Regulation of the tumor suppressor homeogene Cdx2 by HNF4alpha in intestinal cancer. Oncogene 32, 3782-3788 (2013).

29. Kiselyuk, A. et al. HNF4a antagonists discovered by a high-throughput screen for modulators of the human insulin promoter. Chem. Biol. 19, 806-818 (2012).
30. Rodrigues, J. P. et al. Mechanisms of regulation of normal and metaplastic intestinal differentiation. Histol. Histopathol. 33, 523-532 (2018).

31. Mari, L. et al. A pSMAD/CDX2 complex is essential for the intestinalization of epithelial metaplasia. Cell Rep. 7, 1197-1210 (2014).

32. Thompson, C. A., DeLaForest, A. \& Battle, M. A. Patterning the gastrointestinal epithelium to confer regional-specific functions. Dev. Biol. 435, 97-108 (2018).

33. Simmini, S. et al. Transformation of intestinal stem cells into gastric stem cells on loss of transcription factor Cdx2. Nat. Commun. 5, 5728 (2014).

34. Katz, J. P. et al. The zinc-finger transcription factor Klf4 is required for terminal differentiation of goblet cells in the colon. Development 129, 2619-2628 (2002).

35. Kundu, S., Kumar, S. \& Bajaj, A. Cross-talk between bile acids and gastrointestinal tract for progression and development of cancer and its therapeutic implications. IUBMB Life 67, 514-523 (2015).

36. Shi, Y. et al. Deoxycholic acid could induce apoptosis and trigger gastric carcinogenesis on gastric epithelial cells by quantitative proteomic analysis. Gastroent Res. Pr. 2016, 1-10 (2016).

37. Park, M. J., Kim, K. H., Kim, H. Y., Kim, K. \& Cheong, J. Bile acid induces expression of COX-2 through the homeodomain transcription factor CDX1 and orphan nuclear receptor SHP in human gastric cancer cells. Carcinogenesis 29, 2385-2393 (2008)

38. Mosinska, P., Szczepaniak, A. \& Fichna, J. Bile acids and FXR in functional gastrointestinal disorders. Dig. Liver Dis. 50, 795-803 (2018).

39. Guo, C. et al. The G-protein-coupled bile acid receptor Gpbar1 (TGR5) suppresses gastric cancer cell proliferation and migration through antagonizing STAT3 signaling pathway. Oncotarget 6, 34402-34413 (2015).

40. Guo, C. et al. The G-protein-coupled bile acid receptor Gpbar1 (TGR5) inhibits gastric inflammation through antagonizing NF-kappaB signaling pathway. Front Pharm. 6, 287 (2015).

41. Cao, W. et al. Expression of bile acid receptor TGR5 in gastric adenocarcinoma. Am. J. Physiol. Gastrointest. Liver Physiol. 304, G322-G327 (2013).

42. Lau, H. H., Ng, N., Loo, L., Jasmen, J. B. \& Teo, A. The molecular functions of hepatocyte nuclear factors - in and beyond the liver. J. Hepatol. 68, 1033-1048 (2018).

43. Babeu, J. P. \& Boudreau, F. Hepatocyte nuclear factor 4-alpha involvement in liver and intestinal inflammatory networks. World J. Gastroenterol. 20, 22-30 (2014).

44. Garrison, W. D. et al. Hepatocyte nuclear factor $4 a$ is essential for embryonic development of the mouse colon. Gastroenterology 130, 11-19 (2006).

45. Colleypriest, B. J. et al. Hnf4a is a key gene that can generate columnar metaplasia in oesophageal epithelium. Differentiation 93, 39-49 (2017).

46. Rogerson, $\mathrm{C}$. et al. Identification of a primitive intestinal transcription factor network shared between esophageal adenocarcinoma and its precancerous precursor state. Genome Res 29, 723-736 (2019).

47. Tanaka, $T$. et al. Dysregulated expression of $P 1$ and $P 2$ promoter-driven hepatocyte nuclear factor-4a in the pathogenesis of human cancer. J. Pathol. 208, 662-672 (2006).

48. Chang, H. R. et al. HNF4alpha is a therapeutic target that links AMPK to WNT signalling in early-stage gastric cancer. Gut 65, 19-32 (2016).

49. Green, N. H. et al. Pulsatile exposure to simulated reflux leads to changes in gene expression in a 3D model of oesophageal mucosa. Int J. Exp. Pathol. 95, 216-228 (2014).

50. Chellappa, K. et al. Opposing roles of nuclear receptor HNF4alpha isoforms in colitis and colitis-associated colon cancer. Elife 5, e10903 (2016).

51. Kazumori, H., Ishihara, S., Takahashi, Y., Amano, Y. \& Kinoshita, Y. Roles of Kruppel-like factor 4 in oesophageal epithelial cells in Barrett's epithelium development. Gut 60, 608-617 (2011).

52. Chen, B. et al. hTERT promotes gastric intestinal metaplasia by upregulating CDX2 via NF-KB signaling pathway. Oncotarget 8, 26969 (2017).

53. Babeu, J., Darsigny, M., Lussier, C. R. \& Boudreau, F. Hepatocyte nuclear factor 4a contributes to an intestinal epithelial phenotype in vitro and plays a partial role in mouse intestinal epithelium differentiation. Am. J. Physiol. Gastrointest. Liver Physiol. 297, G124-G134 (2009).

54. Bailly, A., Torres-Padilla, M. E., Tinel, A. P. \& Weiss, M. C. An enhancer element 6 $\mathrm{kb}$ upstream of the mouse HNF4alpha1 promoter is activated by glucocorticoids and liver-enriched transcription factors. Nucleic Acids Res. 29, 3495-3505 (2001)

55. Barros, R. et al. CDX2 autoregulation in human intestinal metaplasia of the stomach: impact on the stability of the phenotype. Gut 60, 290-298 (2011). 